\title{
Alveolar epithelial cells orchestrate DC function in murine viral pneumonia
}

\author{
Barbara Unkel, ${ }^{1}$ Katrin Hoegner, ${ }^{1}$ Björn E. Clausen, ${ }^{2}$ Peter Lewe-Schlosser, ${ }^{3}$ \\ Johannes Bodner, ${ }^{4}$ Stefan Gattenloehner, ${ }^{5}$ Hermann Janßen, ${ }^{6}$ \\ Werner Seeger, ${ }^{1}$ Juergen Lohmeyer, ${ }^{1}$ and Susanne Herold ${ }^{1}$
}

\begin{abstract}
1Department of Internal Medicine II, University of Giessen and Marburg Lung Center (UGMLC; member of the German Lung Research Center), Giessen, Germany. ${ }^{2}$ Department of Immunology, Erasmus MC, University Medical Center, Rotterdam, the Netherlands. ${ }^{3}$ Center for Radiation Therapy, ${ }^{4}$ Department of General and Thoracic Surgery, and ${ }^{5}$ Department of Pathology, UGMLC, Giessen, Germany. ${ }^{6}$ Department of Surgery II, Hospital Dueren, Dueren, Germany.
\end{abstract}

\begin{abstract}
Influenza viruses (IVs) cause pneumonia in humans with progression to lung failure. Pulmonary DCs are key players in the antiviral immune response, which is crucial to restore alveolar barrier function. The mechanisms of expansion and activation of pulmonary DC populations in lung infection remain widely elusive. Using mouse BM chimeric and cell-specific depletion approaches, we demonstrated that alveolar epithelial cell (AEC) GM-CSF mediates recovery from IV-induced injury by affecting lung DC function. Epithelial GM-CSF induced the recruitment of CD11b ${ }^{+}$and monocyte-derived DCs. GM-CSF was also required for the presence of $\mathrm{CD} \mathrm{C3}^{+} \mathrm{DCs}$ in the lung parenchyma at baseline and for their sufficient activation and migration to the draining mediastinal lymph nodes (MLNs) during IV infection. These activated $\mathrm{CD}_{103}{ }^{+} \mathrm{DCs}$ were indispensable for sufficient clearance of IVs by $\mathrm{CD8}^{+} \mathrm{T}$ cells and for recovery from IV-induced lung injury. Moreover, GM-CSF applied intratracheally activated $\mathrm{CD} 13^{+} \mathrm{DCs}$, inducing increased migration to MLNs, enhanced viral clearance, and attenuated lung injury. Together, our data reveal that GM-CSF-dependent cross-talk between IV-infected AECs and $\mathrm{CD} \mathrm{C3}^{+} \mathrm{DCs}$ is crucial for effective viral clearance and recovery from injury, which has potential implications for GM-CSF treatment in severe IV pneumonia.
\end{abstract}

\section{Introduction}

Influenza viruses (IVs) may cause primary viral pneumonia in humans with rapid progression to lung failure and fatal outcome (1). Histopathologic and clinical features of IV-induced lung injury in humans resemble those of other forms of adult respiratory distress syndrome (ARDS), characterized by apoptotic alveolar epithelial damage, loss of alveolar barrier function, and severe hypoxemia (1-3). As soon as the infection spreads from the upper to the lower respiratory tract, alveolar epithelial cells (AECs) become primary targets for productive IV replication (3-5). At the same time, AECs release innate immune mediators, which activate myeloid mononuclear phagocytes such as alveolar macrophages or DCs or recruit their precursors to the site of infection (6). Combining sensor and effector functions of innate immunity, the lung epithelium has recently been ascribed an important role in coordinating, maintaining, and balancing the phagocyte-mediated antiviral host response (7). The molecular signals involved in this cellular cross-talk between alveolar epithelium and local mononuclear phagocyte subsets during the host response to viral infection in situ, however, remain largely elusive.

Rapid and effective clearance of IVs from the distal lung is crucial for recovery from IV-induced lung injury. Different $\mathrm{CD} 11 \mathrm{c}^{+} \mathrm{MHCII}$ pulmonary DC subsets critically contribute to pulmonary host defense $(8,9)$. In mice, these include $\mathrm{CD} 11 \mathrm{~b}^{+} \mathrm{CX}_{3} \mathrm{CR} 1^{+} \mathrm{CD} 103^{-}$and $\mathrm{CD}_{103}{ }^{+}$langerin ${ }^{+} \mathrm{CD} 11 \mathrm{~b}^{-}$parenchymal DCs, which form an elaborate network in immediate proximity to AECs to rapidly encounter foreign antigen in the alveolar airspaces and lung interstitium and migrate to the draining mediastinal lymph nodes (MLNs) (10). Several reports demonstrate a key role for the pulmonary

Conflict of interest: The authors have declared that no conflict of interest exists. Citation for this article: J Clin Invest. 2012;122(10):3652-3664. doi:10.1172/JCI62139.
$\mathrm{CD}_{103^{+} \text {langerin }}^{+}$DC subset in antiviral immunity in vitro and in vivo $(11,12)$, and elimination of $\mathrm{CD}_{103}{ }^{+}$langerin ${ }^{+} \mathrm{DCs}$ during IV infection severely impairs induction of the $\mathrm{CD} 8^{+} \mathrm{T}$ cell-mediated response and delays viral clearance (13).

Under steady-state conditions, pulmonary CD $11 \mathrm{~b}^{+}$and $\mathrm{CD} 103^{+}$ DCs arise from circulating GR-1 ${ }^{\text {hi }}$ monocytes and pre-DCs, respectively, and replenishment of their resident pools depends on FLt3/ Flt3L and M-CSF receptor (M-CSFR) (14). During lung infection or inflammation, the inflammatory DC subsets in particular,

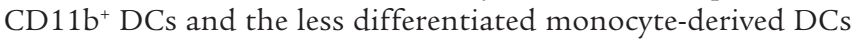
(mo-DCs), are expanded from the circulating GR-1 $1^{\text {hi }}$ monocyte pool, whereas the numbers of $\mathrm{CD} 103^{+}$DCs in lung tissue initially decline due to increased migration to $\operatorname{MLNs}(10,13,15,16)$.

The growth factor GM-CSF is widely recognized as promoting differentiation and mobilization of myeloid cells in vivo and is frequently used to generate DCs from BM- or blood-derived precursors in vitro $(17,18)$. It is crucially involved in antimicrobial pulmonary host defense $(19,20)$ and ameliorates lung injury when applied systemically to IV-infected mice (21) by increasing size and activation of the alveolar macrophage pool $(22,23)$. Previously, 2 studies have demonstrated that GM-CSF drives the accumulation of CD $11 b^{+}$DC populations in the gut lamina propria under homeostatic conditions $(24,25)$. More recently, GM-CSF was shown to expand radiosensitive langerin ${ }^{+} \mathrm{CD}_{103^{+}} \mathrm{DCs}$ in the skin and peripheral lymph nodes under steady-state and inflammatory conditions during autoimmune disease (26). With respect to the lung, however, the mechanisms mediating expansion and/or activation of parenchymal DC subsets during viral infection of the lower respiratory tract - and, in particular, the role of GM-CSF therein - remain to be defined.

Here, using a model of IV pneumonia, we elucidated a crucial role of IV-infected AECs in orchestrating pulmonary DC antiviral functions. Using BM chimeric and cell-specific depletion 
A

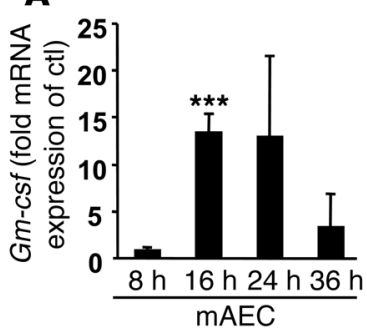

B

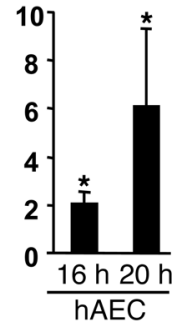

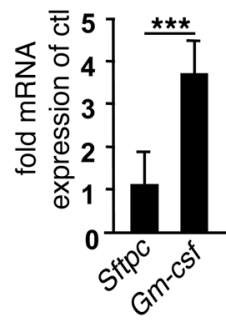
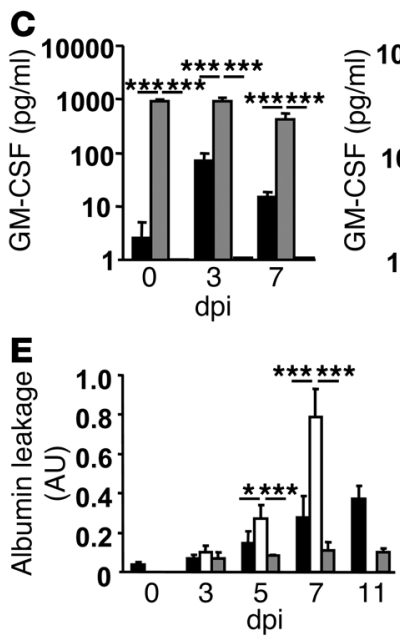

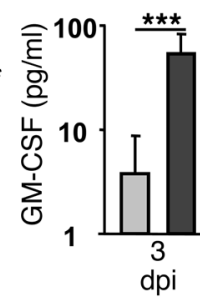

dpi

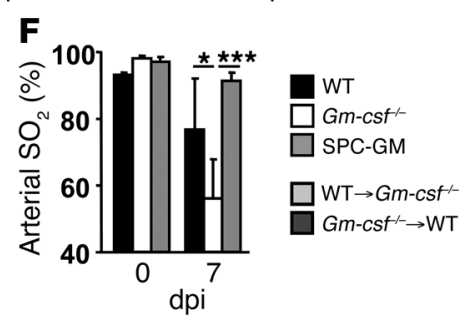

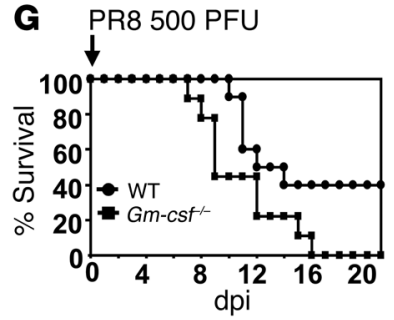

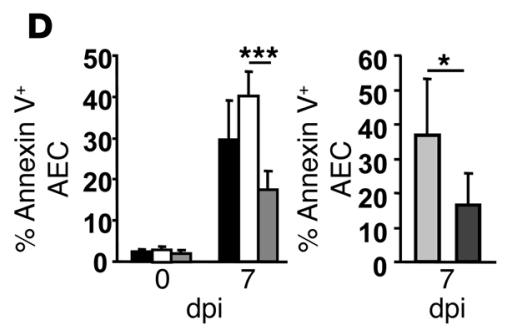

dpi

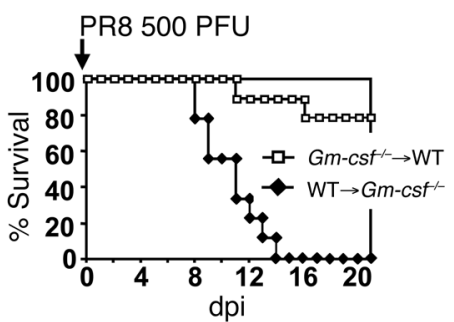

Figure 1

AEC GM-CSF attenuates acute lung injury and increases survival in PR8 infection. (A) Gm-csf mRNA expression in primary murine $(\mathrm{m}-)$ or human (h-) AECs infected with PR8 in vitro. (B) $G m$-csf mRNA induction in purified AECs from PR8-infected WT mice at $3 \mathrm{dpi}$. Expression of the type II AEC marker Sftpc was additionally determined. (C) GM-CSF release in LHs of PR8-infected WT, Gm-csf $f^{-}$, SPC-GM, Gm-csf ${ }^{-1} \rightarrow \mathrm{WT}$, and $\mathrm{WT} \rightarrow \mathrm{Gm}$-csf $f^{-1-}$ mice. (D) AEC apoptosis, determined by quantification of Annexin $\mathrm{V}$ binding to CD45-CD31-EpCam+ LH cells. (E) Alveolar albumin leakage analyzed after PR8 infection. The ratio of BALF and serum FITC fluorescence is expressed in AU. (F) Arterial oxygen saturation $\left(\mathrm{SO}_{2}\right)$. (G) Survival of WT and $\mathrm{Gm}$-csf $f^{--}$mice infected with 500 PFU PR8 $(n=8$ per group), WT and SPC-GM mice infected with 2,000 PFU PR8 $(n=8$ per group), and $\mathrm{Gm}-\mathrm{csf}^{-1-} \rightarrow \mathrm{WT}$ and $\mathrm{WT} \rightarrow \mathrm{Gm}-\mathrm{Csf}^{-/-}$mice infected with 500 PFU PR8 ( $n=9$ per group). Data are mean \pm SD. ${ }^{*} P<0.05$, ${ }^{* * *} P<0.005$ vs. mock-infected control (ctl) or as indicated by brackets. strategies, we showed that AEC GM-CSF released upon IV infection was required for expansion and activation of the CD103+ migratory DC pool and for an appropriate antiviral $\mathrm{T}$ cell-mediated immune response with recovery from IV-induced lung injury. Collectively, our data identified GM-CSF-dependent crosstalk between viral target cells and local DCs in the distal lung and highlighted the AEC GM-CSF/GM-CSFR axis as a potential therapeutic target to increase pulmonary DC antiviral functions in the context of IV-induced lung injury.

\section{Results}

$A E C$ induce recovery from IV-induced lung injury by release of GM-CSF. AECs are primary targets for IVs and, at the same time, represent important effector cells in the host defense of the distal respiratory tract. Upon infection, they release cytokines that shape mononuclear phagocyte immune responses and initiate viral clearance. To address the role of GM-CSF in these processes, we tested whether AECs expressed GM-CSF in response to IV challenge. Indeed, both primary isolated and cultured murine and human AECs significantly upregulated Gm-csf mRNA upon in vitro PR8 infection, most prominent at 16 and 20 hours post infection, respectively (Figure 1A). Accordingly, AECs isolated from the lungs of PR8-infected mice showed increased Gm-csf expression compared with mock-infected controls at 3 days post infection (dpi; Figure 1B). To evaluate whether epithelial GM-CSF affected PR8-induced lung damage, we compared lung injury levels in WT mice, GM-CSF-deficient mice (referred to herein as $G m-c s f^{--}$), and mice that express GM-CSF in AECs only (referred to herein as SPC-GM mice; see Methods). GM-CSF was released into the lungs of WT mice in response to PR8 infection and overexpressed constitutively and during IV infection in SPC-GM lungs compared with Gm-csf $f^{-1}$ mice (Figure 1C). Notably, GMCSF protein was not detectable in the serum of WT or SPC-GM mice at baseline or after PR8 infection (data not shown). Strikingly, lung injury was highly increased in $\mathrm{Gm}$-csf $f^{-}$compared with WT mice, and selective AEC GM-CSF expression in SPC-GM mice fully reverted increased alveolar injury, as demonstrated by analysis of AEC apoptosis, alveolar albumin leakage, and arterial oxygen saturation (Figure 1, D-F). Accordingly, 100\% of Gm-csf $f^{-}$ mice succumbed to infection with 500 PFU PR8 by 16 dpi, whereas $40 \%$ of WT mice survived. Infection with an increased viral dose of 2,000 PFU, however, resulted in $100 \%$ mortality in WT mice by $16 \mathrm{dpi}$, whereas $75 \%$ of SPC-GM mice survived until $21 \mathrm{dpi}$ (Figure $1 \mathrm{G}$ ), which indicates that GM-CSF is crucial to survive severe IV infection and that alveolar overexpression of GM-CSF further attenuates the disease. 
A

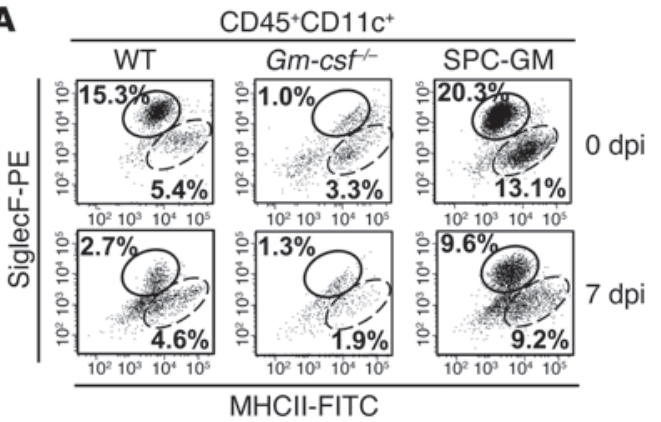

B
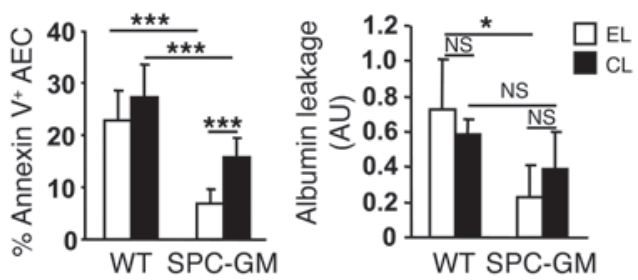
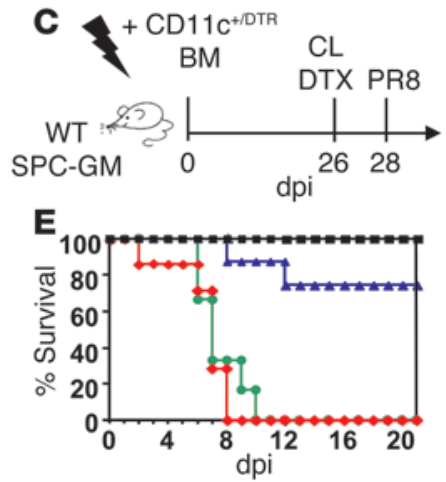

$-\mathrm{CD} 11 \mathrm{c}^{+ \text {DTR }} \rightarrow \mathrm{SPC}-\mathrm{GM}+$ EL/PBS

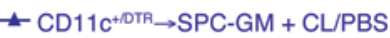

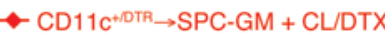

$\bullet \mathrm{CD} 11 \mathrm{c} \mathrm{C}^{+ \text {ITR }} \rightarrow \mathrm{WT}+\mathrm{CL} / \mathrm{DTX}$
D
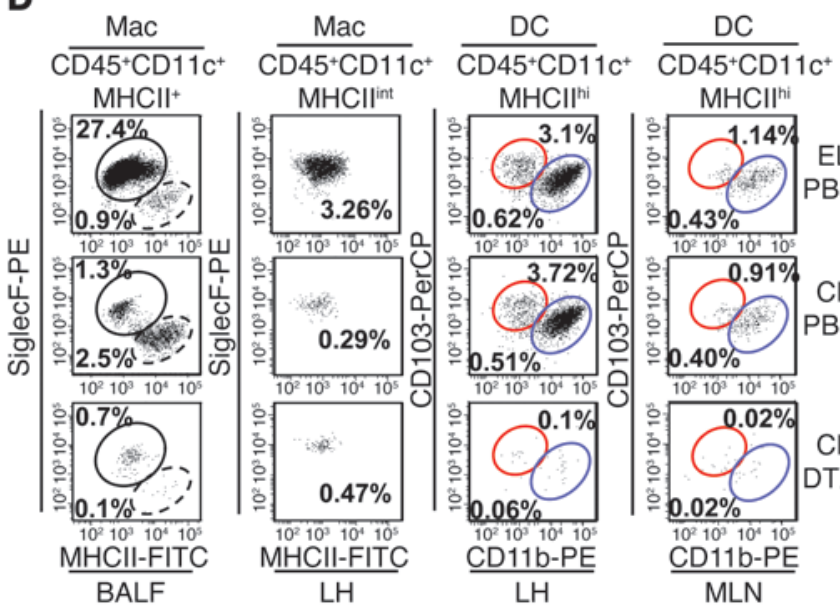

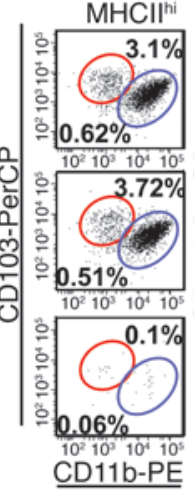

$\mathrm{LH}$

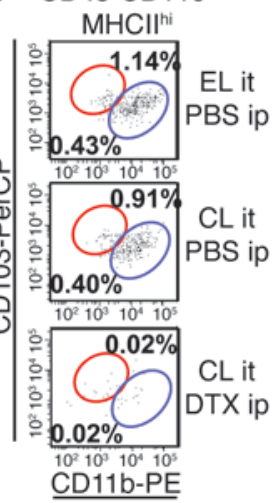

MLN

\section{Figure 2}

Lung-protective effects of AEC GM-CSF are mediated by pulmonary DCs in SPC-GM mice after PR8 infection. (A) FACS quantification of macrophages (Mac; $\mathrm{CD} 45+\mathrm{CD} 11 \mathrm{C}^{+}$SiglecF+MHCIlint; solid line) and DCs (CD45+CD11C+SiglecF-MHCIlli; dashed line) in the lungs of uninfected or PR8-infected (7 dpi) WT, Gm-csf ${ }^{-1-}$, and SPC-GM mice. (B) Mice were i.t. treated with clodronate liposomes (CL) to deplete alveolar macrophages or with empty liposomes (EL) 48 hours prior to PR8 infection, and AEC apoptosis and alveolar albumin leakage were determined at 7 dpi. (C) Treatment protocol. WT and SPC-GM mice were lethally irradiated and transplanted $1 \times 10^{6} \mathrm{CD}_{11 \mathrm{C}^{+/ D T R}} \mathrm{BM}$ cells to generate CD11C $+/$ DTR $\rightarrow$ WT or CD11 $\mathrm{C}^{+/ \mathrm{DTR}} \rightarrow$ SPC-GM chimeric mice. 26 days later, when $>90 \%$ of lung DCs were of CD11C $\mathrm{C}^{+/ \mathrm{DTR}}$ donor phenotype (whereas alveolar macrophages were mainly of recipient CD11 $\mathrm{c}^{+/+}$phenotype), chimeras were treated with clodronate or empty liposomes i.t. and with DTX or PBS i.p. to deplete lung macrophages and DCs, respectively, then infected with PR8 48 hours later. (D) Depletion efficacy in CD11 $\mathrm{C}^{+/ D T R} \rightarrow$ WT chimeras

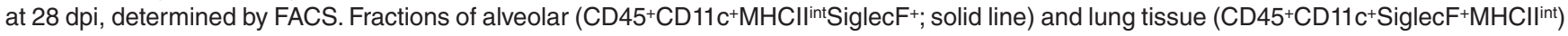
macrophages and of alveolar DCs (CD45+CD11 $\mathrm{c}^{+} \mathrm{MHCII}^{\mathrm{h}}$ SiglecF-; dashed line) were determined from BALF and LH, respectively, and fractions of $\mathrm{CD} 45^{+} \mathrm{CD} 11 \mathrm{C}^{+} \mathrm{MHCl}{ }^{\mathrm{hi}} \mathrm{CD} 103^{+}$(red gates) and CD45+CD11 $\mathrm{c}^{+} \mathrm{MHCI}$ hi CD11 b+ (blue gates) DCs were determined from LH and MLNs. (E) Survival of clodronate liposome/DTX-treated CD11 + $^{+/ D T R} \rightarrow$ WT mice and empty liposome/PBS-, clodronate liposome/PBS-, or clodronate liposome/DTXtreated CD11C ${ }^{+/ D T R} \rightarrow$ SPC-GM mice after PR8 infection $(n=7-8)$. Data are mean \pm SD. ${ }^{*} P<0.05,{ }^{* * *} P<0.005$.

In the lung, GM-CSF is expressed not only by AECs, but also by resident or recruited myeloid cells or further cell types (17), and various distal lung cell subsets were reported to be IV targets. We therefore analyzed in detail which alveolar cell populations were targets of PR8 during the course of infection. Significant numbers of type I and II AECs and CD11 $\mathrm{c}^{+}$leukocytes were PR8 infected by 3 dpi, whereas ECs were hardly and neutrophils (data not shown) were not infected (Supplemental Figure 1A; supplemental material available online with this article; doi:10.1172/JCI62139DS1). We next analyzed which parenchymal cell types of the distal respiratory tract represented primary sources of GM-CSF after infection. Comparison of Gm-csf mRNA levels in flow-sorted type I and II AECs, bronchiolar epithelial cells (BECs; ref. 27), and endothelial cells revealed that type I AECs, BECs, and endothelial cells showed low baseline expression and no significant upregulation of GM-CSF at $3 \mathrm{dpi}$ (Supplemental Figure 1C). Type II AECs showed the highest GM-CSF expression at baseline and, apart from bronchoalveo- lar lavage fluid (BALF) leukocytes (which were mainly composed of resident alveolar macrophages and neutrophils, Supplemental Figure 1B), were the only lung cell population that significantly upregulated Gm-cs $f$ mRNA upon PR8 challenge. Notably, separated and cultured AECs from lungs of untreated WT mice showed GM-CSF release into the supernatants compared with endothelial cells or alveolar macrophages ( $180 \mathrm{pg} / \mathrm{ml}$; data not shown). Given that type II AECs represented the most frequent parenchymal cells in distal lungs ( $>90 \%$; data not shown) and a substantial type II AEC proportion was PR8 infected, we concluded that AECs are the primary source of GM-CSF in the distal lung at baseline and in particular upon PR8 infection.

To further discriminate the role of AECs as opposed to myeloid GM-CSF in the observed effects, we infected WT or Gm-csf/- mice that were reciprocally BM transplanted and, after reconstitution for 56 days, displayed resident alveolar macrophages (Supplemental Figure 2A) and circulating leukocytes of donor origin. 
A
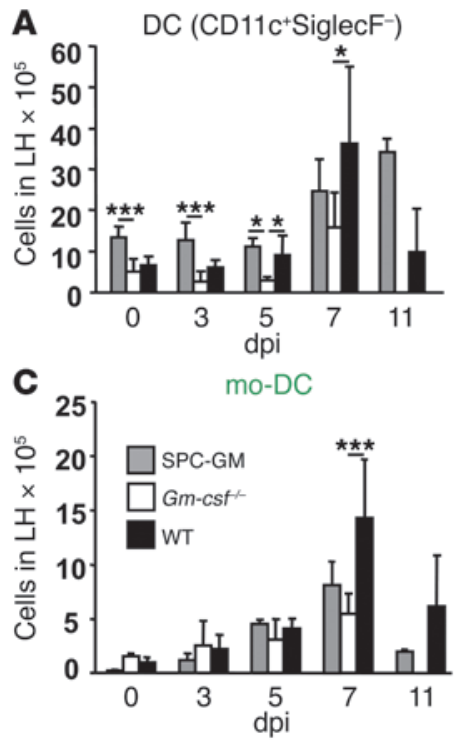

$\mathrm{CD}^{+} 5^{+} \mathrm{CD} 11 \mathrm{C}^{+} \mathrm{MHCI}{ }^{\mathrm{h}} \mathrm{B} 220^{-}$

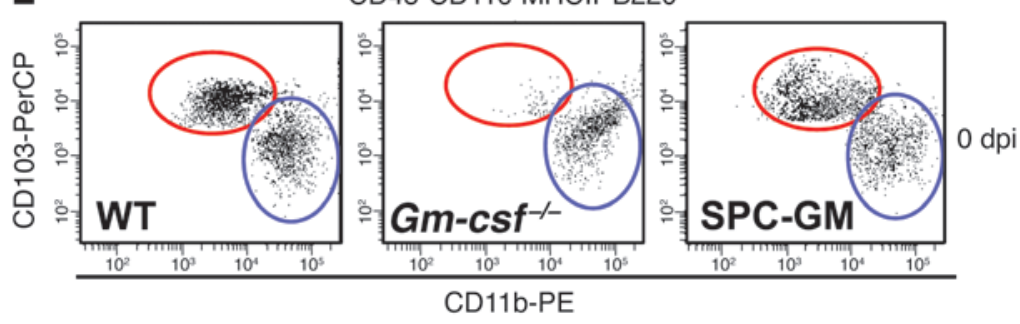

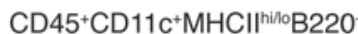
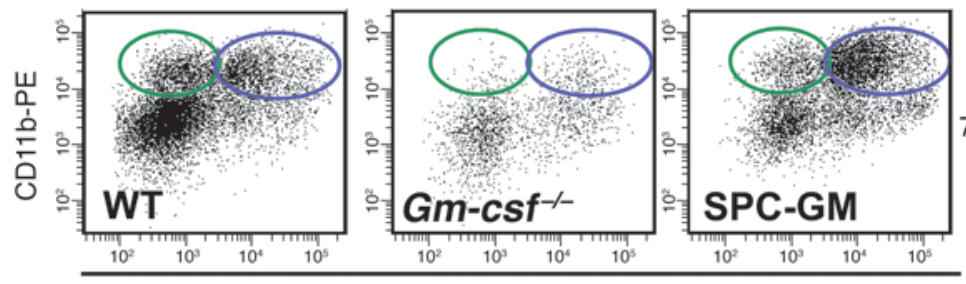

MHCII-FITC

Figure 3

AEC GM-CSF is required for accumulation of DC populations in the lung under steady-state conditions and after PR8 infection. SPC-GM, Gm-csf--- and WT mice were PR8 infected, and the number of total $\mathrm{CD}_{4} 5^{+} \mathrm{CD} 11 \mathrm{c}^{+} \mathrm{MHClI}^{-} / \mathrm{hiS}^{-}$iglecF ${ }^{-}$ DCs (A), CD11 b+ DCs (CD45+CD11 ${ }^{+}$MHCI hi B220-CD103-CD11 b+; B), moDCs (CD45+CD11 c+MHCII ${ }^{\circ}$ B220-CD 103-CD11 b+; C), and CD $103^{+}$DCs $\left(\mathrm{CD} 45^{+} \mathrm{CD} 11 \mathrm{C}^{+} \mathrm{MHCl}{ }^{\text {hi }} \mathrm{B} 220^{-} \mathrm{CD} 103^{+}\right.$; D $)$were quantified by counting $\mathrm{LH}$ cells and flow cytometric quantification of the respective proportions (see Supplemental Figure 3 for gating strategy). (E) Representative dot plots for lung DC subpopulations from uninfected $\left(\mathrm{CD} 11 \mathrm{~b}^{+}\right.$, blue gates; $\mathrm{CD}_{103^{+}}$, red gates, gated from $\mathrm{CD} 45^{+} \mathrm{CD} 11 \mathrm{C}^{+} \mathrm{MHCl}{ }^{\text {hi }}{ }^{\mathrm{B} 220^{-}}$ $\mathrm{LH}$ cells) and PR8-infected $\left(\mathrm{CD} 11 \mathrm{~b}^{+}\right.$, blue gates; mo-DC, green gates, gated from $\mathrm{CD} 45^{+} \mathrm{CD} 11 \mathrm{C}^{+} \mathrm{MHCl}{ }^{\text {hillo }} \mathrm{B} 220^{-} \mathrm{LH}$ cells) mice. Data are mean $\pm \mathrm{SD}$. ${ }^{\star} P<0.05,{ }^{* * *} P<0.005$.

$\mathrm{WT} \rightarrow \mathrm{Gm}$-csf ${ }^{-1}$ mice (with WT myeloid GM-CSF expression) showed very low GM-CSF levels in their lungs and increased lung injury after PR8 infection compared with $\mathrm{Gm}^{-c s f^{--} \rightarrow \text { WT mice }}$ (with lung parenchymal cell GM-CSF expression), as demonstrated by analysis of AEC apoptosis (Figure 1, C and D). Moreover, PR8-induced mortality was highly increased in chimeric mice lacking epithelial GM-CSF expression compared with those lacking GM-CSF in myeloid cells (Figure 1G). Together, our data demon- strated that AECs are a primary source of GM-CSF in the PR8-infected lung and that lung parenchymal, but not myeloid cell-expressed, GM-CSF protects mice from IV-induced lung injury.

Lung-protective effects of AEC GM-CSF in IV pneumonia are mediated by pulmonary DCs. Recent reports demonstrated that AEC GM-CSF specifically enhanced host defense functions of resident alveolar macrophages during IV infection (22). To further dissect the contribution of lung mononuclear phagocyte subtypes to the beneficial effects of epithelial GM-CSF, we determined the numbers of macrophages and DCs in lung digests of WT, Gm-csf/-, and SPC-GM mice. As shown in a representative FACS plot in Figure 2A, AEC GM-CSF was required for the presence of both $\mathrm{CD}_{11 \mathrm{c}^{+} \text {SiglecF }}{ }^{+} \mathrm{MHCII}{ }^{\text {int }}$ alveolar macrophages and lung CD $11 \mathrm{c}^{+}$SiglecF-MHCII ${ }^{\text {hi }}$ DCs at baseline and during PR8 infection (7 dpi). We next addressed whether resident alveolar macrophages account for the observed beneficial effects of AEC GM-CSF. Depletion of alveolar macrophages prior to PR8 infection did not increase AEC apoptosis or albumin leakage in WT mice. Although macrophage depletion in SPC-GM mice resulted in increased IVinduced epithelial apoptosis, AEC apoptosis and alveolar albumin leakage were still significantly reduced in SPC-GM compared with WT mice (Figure 2B), suggestive of further macrophage-independent GM-CSF-mediated effects. Of note, PR8 titers in BALF at 7 dpi were not significantly increased in WT or SPC-GM mice after macrophage depletion (Supplemental Figure 2). To further dissect the role of alveolar macrophages versus DCs in our model, we generated BM chimeric WT and SPC-GM mice that were reconstituted with $\mathrm{CD} 11 \mathrm{c}^{+/ \mathrm{DTR}} \mathrm{BM}$ after irradiation. In these chimeric mice, lung and MLN DCs were of CD11 $\mathrm{c}^{+/ \mathrm{DTR}}$ donor phenotype (Supplemental Figure 3 , A and B), whereas the majority of alveolar macrophages was of CD $11 \mathrm{c}^{+/+}$recipient phenotype at 28 days post BM transplantation. This model allows selective depletion of lung and MLN CD11b ${ }^{+}$and CD103+ DCs (CD11 $\left.\mathrm{c}^{+} \mathrm{MHCII}{ }^{\text {hi }}\right)$ by systemic diphtheria toxin (DTX) application and of alveolar and lung parenchymal macrophages $\left(\mathrm{CD} 11 \mathrm{c}^{+} \mathrm{MHCII}^{\text {int }}\right.$ Siglec ${ }^{+} \mathrm{F} 4 / 80^{+}$) by intra-alveolar clodronate deposition (Figure 2, $\mathrm{D}$ and $\mathrm{E})$. Whereas all control-treated $\mathrm{CD} 11 \mathrm{c}^{+/ \mathrm{DTR}} \rightarrow$ SPC-GM mice survived PR8 infection, macrophagedepleted $\mathrm{CD} 11 \mathrm{c}^{+/ \mathrm{DTR}} \rightarrow \mathrm{SPC}-\mathrm{GM}$ mice showed a slightly decreased survival rate of $75 \%$, indicative of a minor role for lung macrophages in the observed effects of AEC-derived GM-CSF on IV-induced mortality. In striking contrast, additional depletion of DCs resulted in a $100 \%$ mortality rate in CD11 $c^{+/ D T R} \rightarrow$ SPC-GM mice at $8 \mathrm{dpi}$, with a comparable course of mortality in doubledepleted CD $11 \mathrm{c}^{+/ D T R} \rightarrow$ WT mice (Figure 2E). These data indicate that AEC GM-CSF exerts its beneficial effects on IV-induced lung injury primarily by its effect on lung DCs.

AEC GM-CSF is required for both homeostasis at baseline and expansion of pulmonary DC subsets during IV infection. Given that steady-state homeostasis and IV-induced expansion of CD11 $\mathrm{c}^{+} \mathrm{MHCII}{ }^{\text {hi }}$ DCs in 

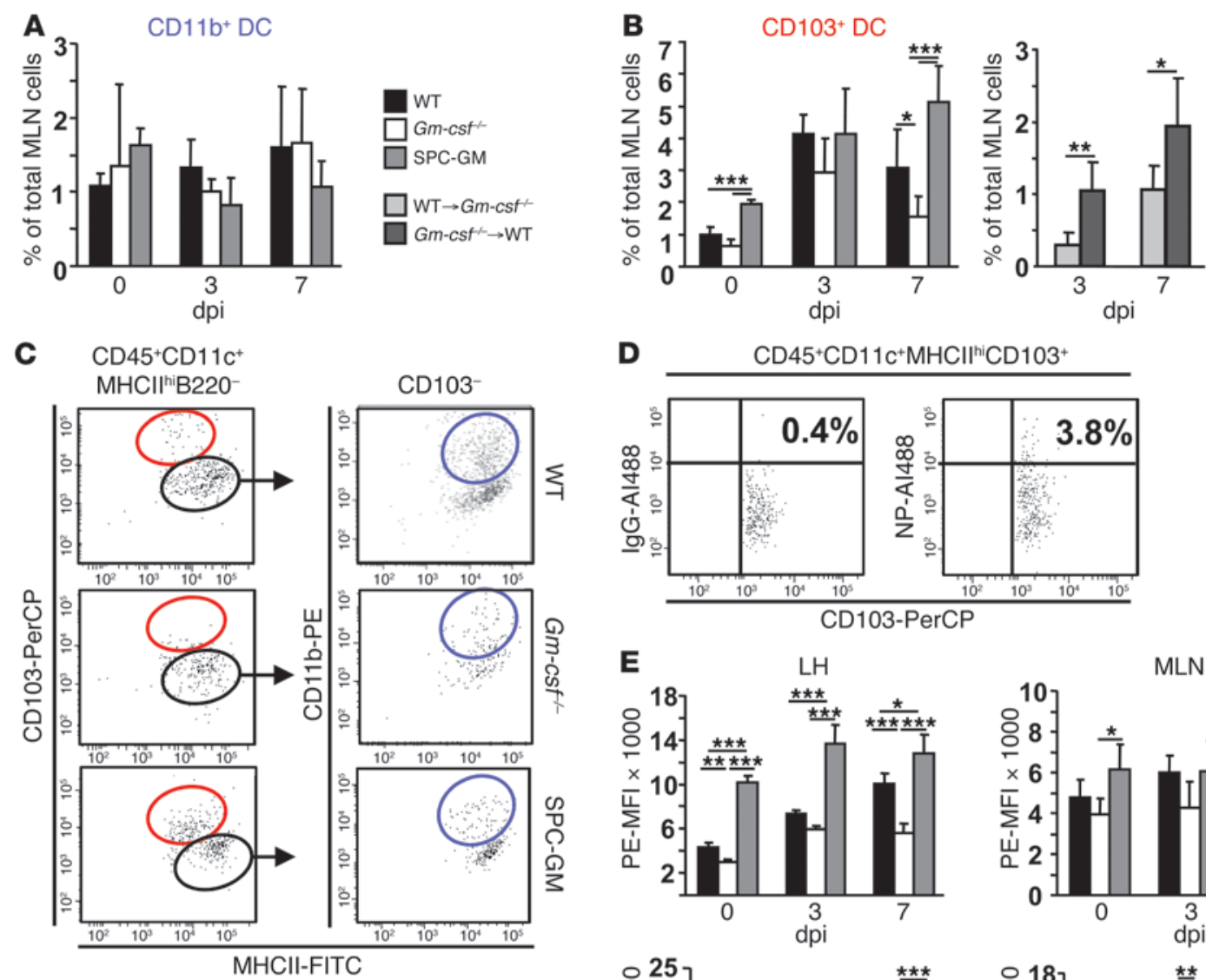

D
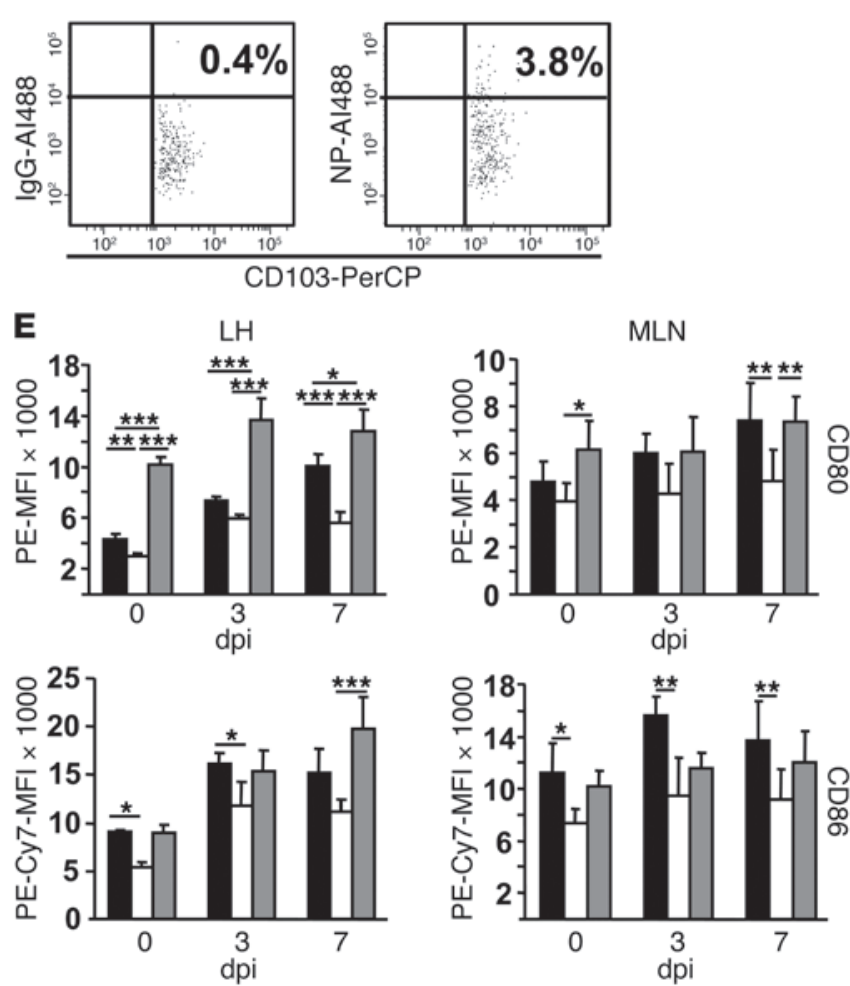

Figure 4

AEC GM-CSF is required for CD103+ DC activation and migration to draining MLNs under steady-state conditions and upon PR8 infection. $\left(\mathbf{A}\right.$ and B) WT, Gm-Csf ${ }^{-1}$, SPC-GM, WT $\rightarrow \mathrm{Gm}-\mathrm{Csf}^{-1-}$, and $\mathrm{Gm}-\mathrm{Csf}^{-1-} \rightarrow \mathrm{WT}$ mice were PR8 infected, and the fractions of CD11b+ DCs $(\mathbf{A})$ and CD103+ DCs (B) in MLNs were quantified by flow cytometry using the gating strategy in C (red gates, CD103+ DCs; blue gates, CD11b+ DCs). (D) Migratory CD $103^{+}$DCs from LH of WT mice were additionally stained for IV NP or control IgG at 5 dpi. Representative FACS plot depicts the NP+ fraction of $\mathrm{CD} 45^{+} \mathrm{CD} 11 \mathrm{C}^{+} \mathrm{MHCI}{ }^{\mathrm{hi}} \mathrm{CD} 103^{+} \mathrm{DCs}$. (E) Comparative flow cytometric quantification of CD80 and CD86 expression on lung and MLN CD103+ DCs after PR8 infection. Values are given as mean intensities $\times 1,000$ of PE (CD80) and PE-Cy7 (CD86) fluorescence. Data are mean \pm SD. ${ }^{*} P<0.05,{ }^{* *} P<0.01,{ }^{* *} P<0.005$.

lung parenchyma was dependent on AEC GM-CSF, we questioned whether expansion of different lung DC subsets shows an equivalent extent of GM-CSF dependency. Figure 3A shows a time course of total numbers of lung CD11 $\mathrm{c}^{+} \mathrm{MHCII}{ }^{\text {hi }} \mathrm{DCs}$ in WT, Gm-csf/-, and SPC-GM mice, demonstrating their GM-CSF-dependent expansion throughout the course of PR8 infection. DC subset differentiation (see Supplemental Figure 4 for gating strategy) revealed that the amount of CD11 $\mathrm{b}^{+}$DCs and mo-DCs at baseline conditions was independent of AEC GM-CSF, but both DC subsets accumulated to high numbers in the lung parenchyma after PR8 infection until $7 \mathrm{dpi}$ only in the presence of AEC GM-CSF (Figure 3, B and C). In contrast, $\mathrm{CD}_{103}{ }^{+} \mathrm{DC}$ numbers generally declined until 5-7 dpi in WT and SPC-GM mice, and their presence at baseline and throughout the course of infection was widely reduced in Gm-csf $f^{-}$ mice (Figure 3D), which indicates that steady-state homeostasis of $\mathrm{CD}_{103}{ }^{+}$DCs was GM-CSF dependent and that selective AEC overexpression of GM-CSF was sufficient to restore lung $\mathrm{CD}_{103^{+} \mathrm{DC}}$ composition. Figure 3E shows a representative FACS plot of DC subsets in the 3 treatment groups at baseline $\left(\mathrm{CD} 103^{+}\right.$and $\mathrm{CD} 11 \mathrm{~b}^{+}$ DCs) and $7 \mathrm{dpi}$ (mo-DCs and CD11 $\left.\mathrm{b}^{+} \mathrm{DCs}\right)$. Of note, accumulation of CD11 $\mathrm{c}^{+} \mathrm{MHCII}^{\mathrm{lo}} \mathrm{B} 220^{+}$plasmacytoid DCs in infected lungs was not dependent on GM-CSF (data not shown).

AEC GM-CSF mediates activation of $C D 103^{+} D C s$ and migration to the draining MLNs following IV infection. To evaluate whether AEC GM-CSF affect accumulation of pulmonary DC subsets in the MLNs, we quantified their numbers in uninfected and PR8- 

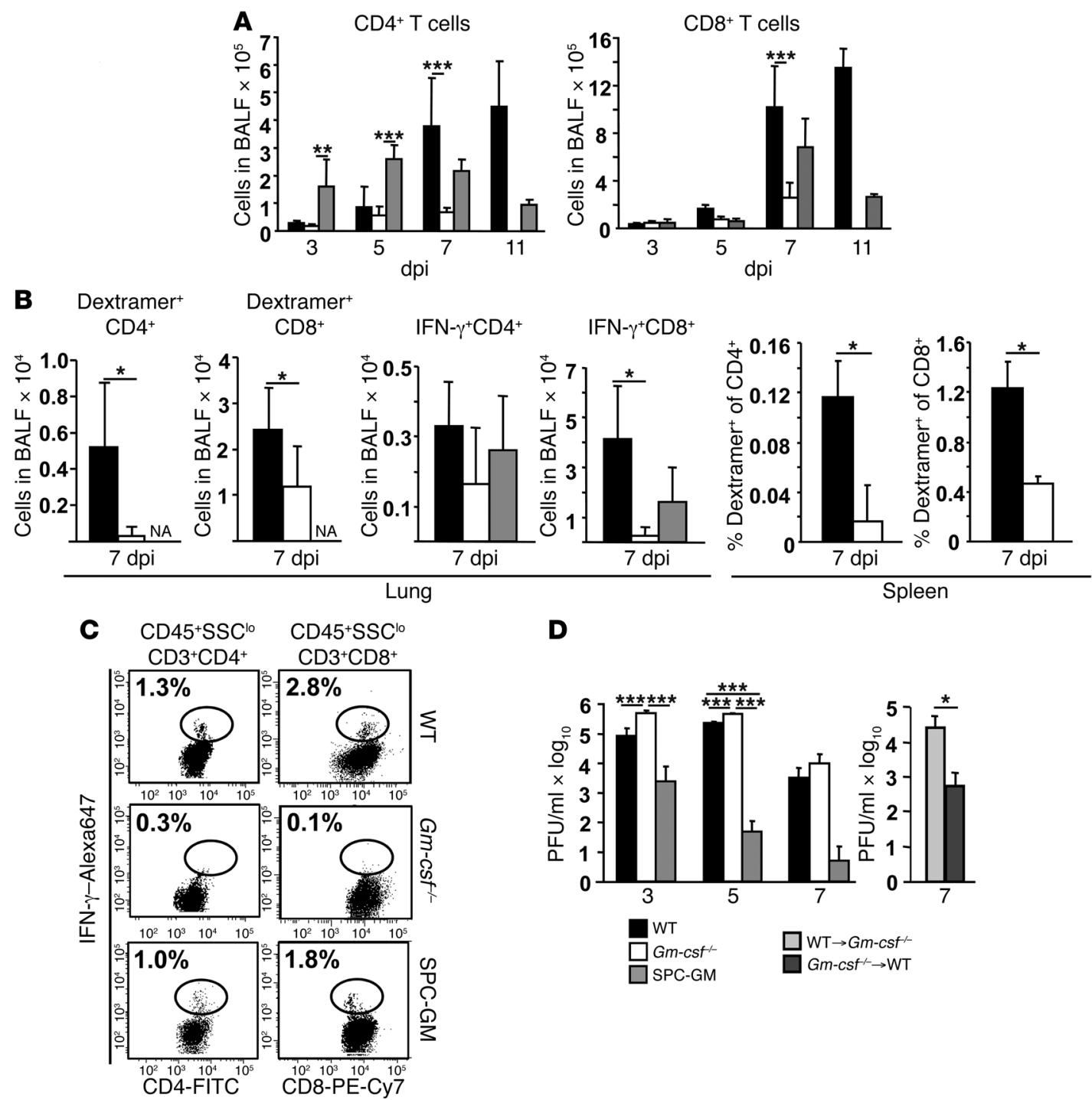

D

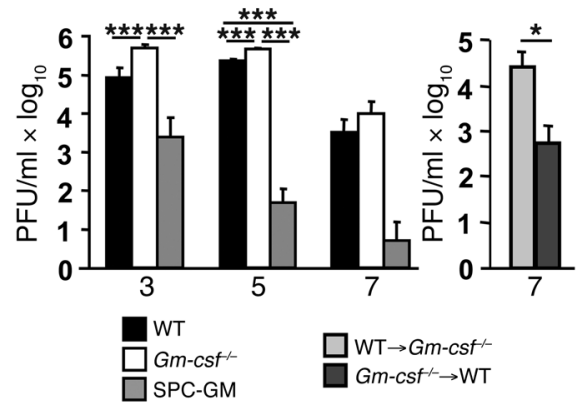

Figure 5

AEC GM-CSF is required for alveolar antiviral CD8 ${ }^{+} T$ cell responses and PR8 clearance from mouse lungs. (A) Absolute numbers of CD4+ and $\mathrm{CD} 8^{+} \mathrm{T}$ lymphocytes in BALF were determined by counting BALF cells and by flow cytometric quantification of the $\mathrm{CD} 45^{+} \mathrm{SSClo} C D 3^{+} \mathrm{CD} 4^{+}$and $\mathrm{CD}_{4}{ }^{+} \mathrm{SSC}^{\circ}{ }^{\circ} \mathrm{CD} 3^{+} \mathrm{CD} 8+$ fractions, respectively, after PR8 infection in WT, Gm-csf--, and SPC-GM mice. (B) Antigen-specific CD4+ and CD8 ${ }^{+} \mathrm{T}$ cell numbers in BALF or spleen, determined by analysis of the $\mathrm{NP}_{\text {peptide }} / \mathrm{H} 2-\mathrm{D}^{\mathrm{b}}$ dextramer ${ }^{+}$or the IFN- $\gamma^{+}$fraction of $\mathrm{CD} 45^{+} \mathrm{SSCl}{ }^{10} \mathrm{CD} 3^{+} \mathrm{CD} 4{ }^{+}$and $\mathrm{CD} 45^{+} \mathrm{SSC}^{10} \mathrm{CD}{ }^{+} \mathrm{CD}^{+}$cells, respectively, after PR8 infection (7 dpi). (C) Representative FACS plots of the IFN- $\gamma$ analysis; percent values of the respective IFN- $\gamma^{+}$proportions are shown in each plot. (D) PR8 titers in WT, Gm-csf ${ }^{-1}$, SPC-GM, WT $\rightarrow \mathrm{Gm}-\mathrm{csf}^{-1}$, and Gm-csf $f^{-1} \rightarrow \mathrm{WT}$ mice, quantified from BALF at the indicated dpi by standard plaque assay and given as PFU $/ \mathrm{ml} \times \log _{10}$ (detection limit, $10^{1} \mathrm{PFU} / \mathrm{ml} \times \log _{10}$ ). Data are $\mathrm{mean} \pm \mathrm{SD}$. ${ }^{\star} P<0.05,{ }^{\star \star} P<0.01,{ }^{\star \star *} P<0.005$. SSC, side scatter.

infected WT, Gm-csf/- and SPC-GM mice. mo-DCs were virtually undetectable in MLNs (data not shown). Unlike CD11 $\mathrm{b}^{+}$ and $\mathrm{CD}^{+}$DCs, which were found in low amounts in MLNs of uninfected and infected mice of all treatment groups (Figure 4, $A$ and $C$, and data not shown), CD $103^{+}$DCs accumulated in the draining MLNs in a GM-CSF-dependent manner during PR8 infection (Figure 4, B and C). Of note, lack of epithelial as opposed to myeloid cell GM-CSF caused reduced numbers of $\mathrm{CD}_{103}{ }^{+}$DCs in MLNs of WT $\rightarrow$ Gm-csf $f^{/-}$versus $G m-c s f^{/-} \rightarrow$ WT chimeric mice, and AEC overexpression of GM-CSF in SPC-GM mice even resulted in significantly increased CD $103^{+}$DC numbers at baseline and at $7 \mathrm{dpi}$ compared with WT mice (Figure 4B), which suggests that AEC GM-CSF increases migration of lung $\mathrm{CD} 103^{+}$DCs to draining MLNs. Migration and activation of DCs is, at least in part, induced by sampling and processing of foreign antigen at the site of infection. In fact, approximately $4 \%$ of pulmonary CD $103^{+}$DCs stained positive for IV nucleoprotein (NP; Figure 4D), indicative of antigen uptake by this DC subset in the lung parenchyma, a characteristic feature of migratory DCs. To address whether epithelial GM-CSF is specifically required for $\mathrm{CD} 103^{+}$DC activation, surface expression of DC activation markers CD80 and CD86 were quantified in all treatment groups. Indeed, expression of activation markers on lung homogenate (LH) $\mathrm{CD} 103^{+} \mathrm{DCs}$ was, at least in part, depen- 
A

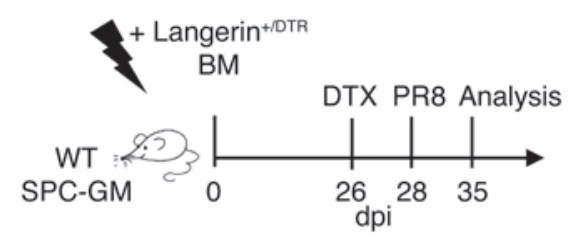

B

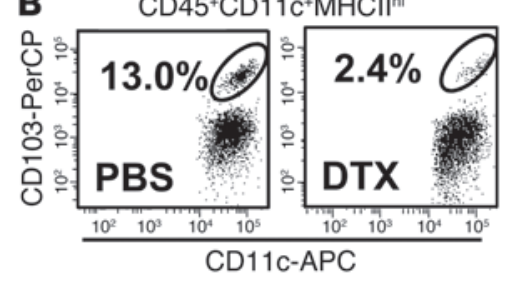

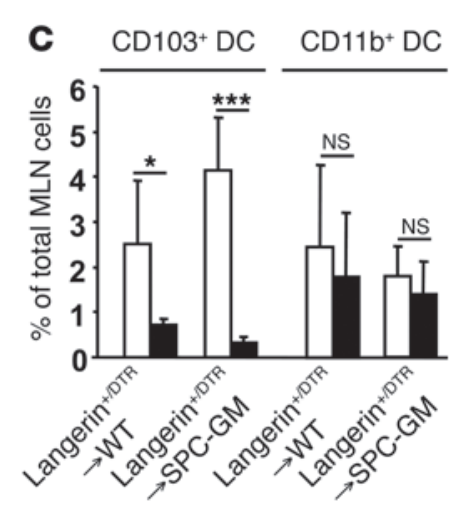

$\mathbf{F}$

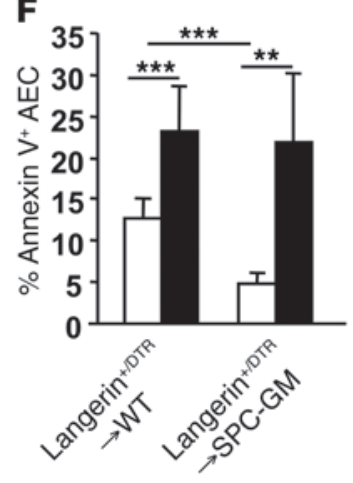

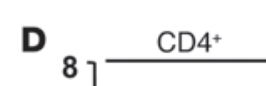
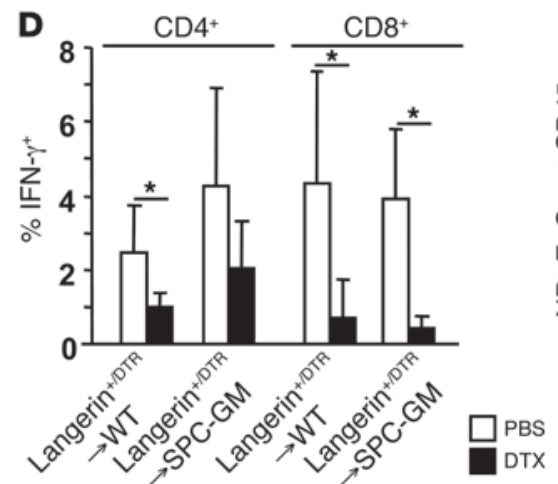

E
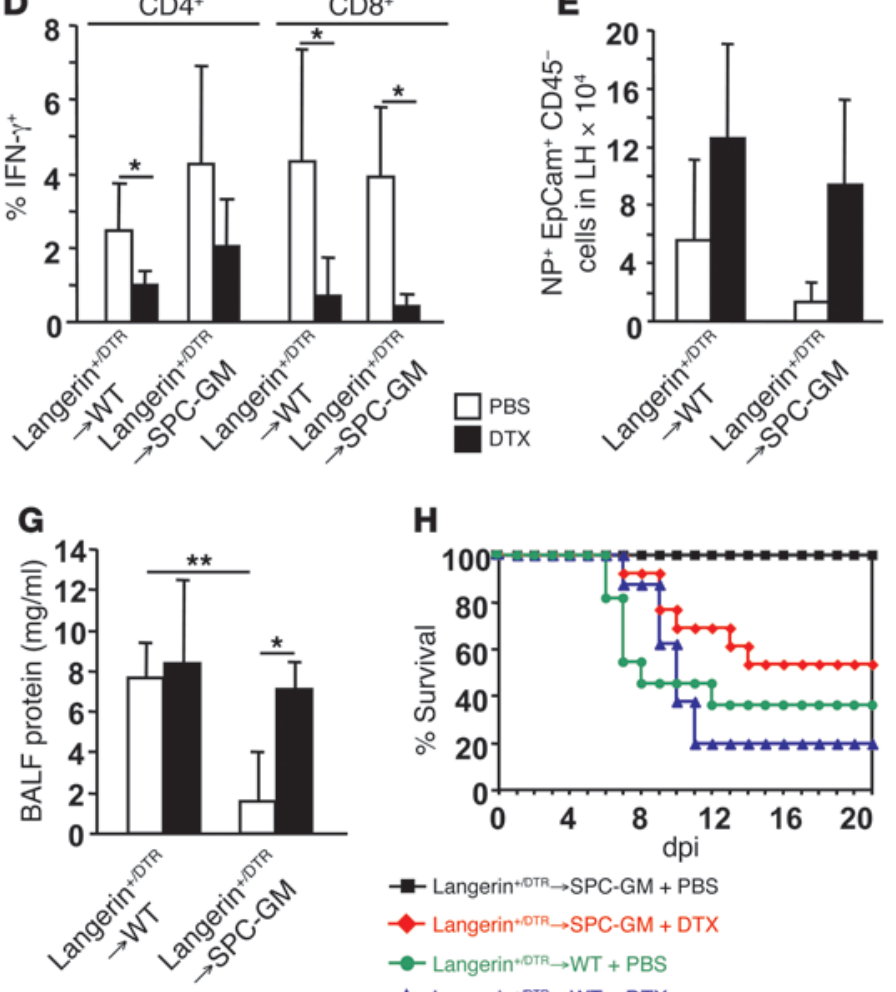

H

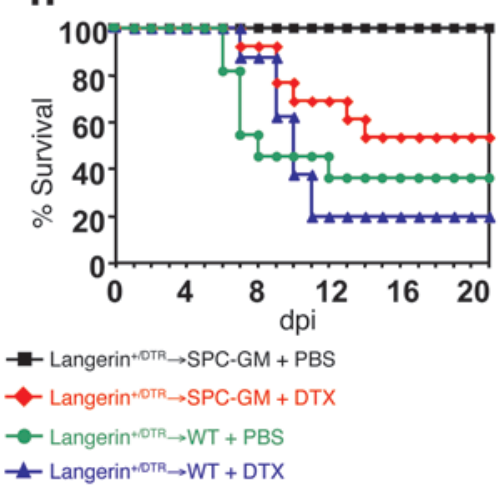

\section{Figure 6}

Lung-protective effects of AEC GM-CSF are mediated by CD103+ lung DCs. (A) Treatment protocol. WT or SPC-GM mice were transplanted $1 \times 10^{6}$ Langerin+/DTR BM cells to generate Langerin ${ }^{+/ D T R} \rightarrow$ WT or Langerin+/DTR $\rightarrow$ SPC-GM chimeric mice. 26 days later, when $>90 \%$ of lung DCs were of Langerin ${ }^{+/ D T R}$ donor phenotype, mice were treated with either DTX or PBS to deplete CD103+ DCs, then infected with PR8 48 hours later for further analyses at $35 \mathrm{dpi}$. (B) At $28 \mathrm{dpi}$, efficacy of CD103+ $\mathrm{DC}$ depletion after PBS or DTX treatment was analyzed by FACS. The CD103+ fraction of $\mathrm{CD} 45+\mathrm{CD} 11 \mathrm{C}+\mathrm{MHCl}$ hi $\mathrm{LH}$ cells was determined after gating on the $\mathrm{CD} 45+\mathrm{CD} 11 \mathrm{c}+\mathrm{MHCl}$ hi population; percentage values are given. At $7 \mathrm{dpi}$, the fractions of $\mathrm{CD}_{103} 3^{+}$and $\mathrm{CD} 11 \mathrm{~b}^{+} \mathrm{DCs}$ in MLNs were quantified (C), using the gating strategy in Figure 3C; the proportions of IFN- $\gamma^{+}$ of $\mathrm{CD}^{+}$and $\mathrm{CD}^{+} \mathrm{T}$ cells in BALF were quantified (D), as outlined in Figure 5C; and the fractions of NP+ EpCam+CD45- epithelial cells in LHs were determined by FACS $(E)$, depicted as absolute numbers in Langerin ${ }^{+/ D T R} \rightarrow$ WT and Langerin $+/ D T R \rightarrow S P C-G M$ chimeric mice after PBS or DTX application. (F) AEC apoptosis in chimeric mice after PBS or DTX application was analyzed by FACS quantification of annexin V binding to CD45-CD31-EpCam+ LH cells at 7 dpi, and (G) total protein was determined in BALF. (H) Survival of PR8-infected chimeric mice after PBS or DTX treatment $(n=8-13)$. Data are mean \pm SD. ${ }^{\star} P<0.05,{ }^{* \star} P<0.01,{ }^{* \star \star} P<0.005$.

dent on AEC GM-CSF in uninfected and PR8-infected mice. After migration to MLNs, CD80 and CD86 expression was still reduced in $\mathrm{CD}_{103}{ }^{+} \mathrm{DCs}$ in $\mathrm{Gm}-\mathrm{csf} \mathrm{f}^{--}$mice at $7 \mathrm{dpi}$ (Figure 4E). Together, our data demonstrated that AEC GM-CSF mediates maturation and MLN migration of pulmonary CD $103^{+}$DCs.

AEC GM-CSF mediates recruitment of activated $C D 8^{+} T$ cells, associated with IV clearance from the lungs. Migratory CD $103^{+} \mathrm{DCs}$ were shown to preferentially drive antigen presentation to naive $\mathrm{CD}^{+}$ $\mathrm{T}$ cells in the MLNs following IV infection (12), which are then recruited to the lung to clear infection. To test the role of epithelial GM-CSF herein, we quantified numbers of $\mathrm{T}$ cell subsets in the alveolar space during the course of PR8 infection. CD4 ${ }^{+}$ and $\mathrm{CD}^{+} \mathrm{T}$ cells accumulated in BALF until $11 \mathrm{dpi}$ in WT mice, whereas GM-CSF deficiency abrogated this T cell response. Epithelial GM-CSF expression, however, largely restored alveolar T cell accumulation in SPC-GM mice (Figure 5A). Of note, AEC GM-CSF was required for the accumulation of antigen-specific $\mathrm{NP}_{\text {peptide-dextramer }}{ }^{+}$or IFN- $\gamma^{+} \mathrm{CD}^{+}$and IFN- $\gamma^{+} \mathrm{CD}^{+} \mathrm{T}$ cells in the airspaces or in spleen (Figure 5B). Figure 5C depicts representative FACS plots showing the proportion of IFN $-\gamma^{+} \mathrm{CD} 4^{+}$and IFN- $\gamma^{+} \mathrm{CD}^{+} \mathrm{T}$ cells in BALF in the 3 treatment groups at $7 \mathrm{dpi}$. Accordingly, lung viral loads were significantly increased in Gm-csf/- 
A
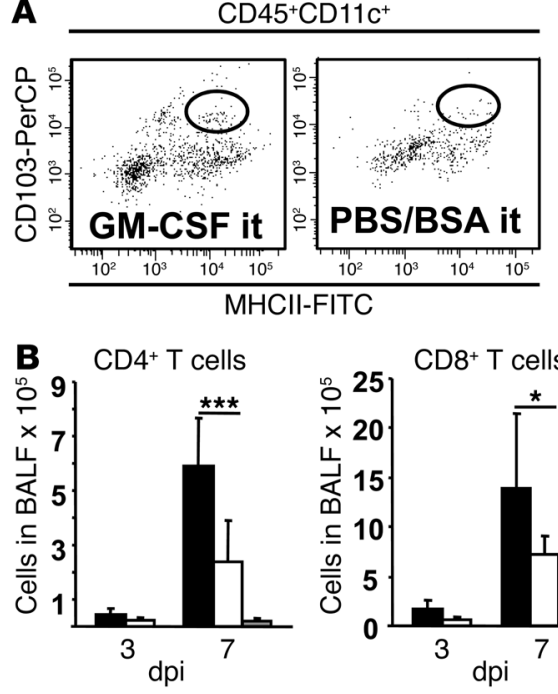
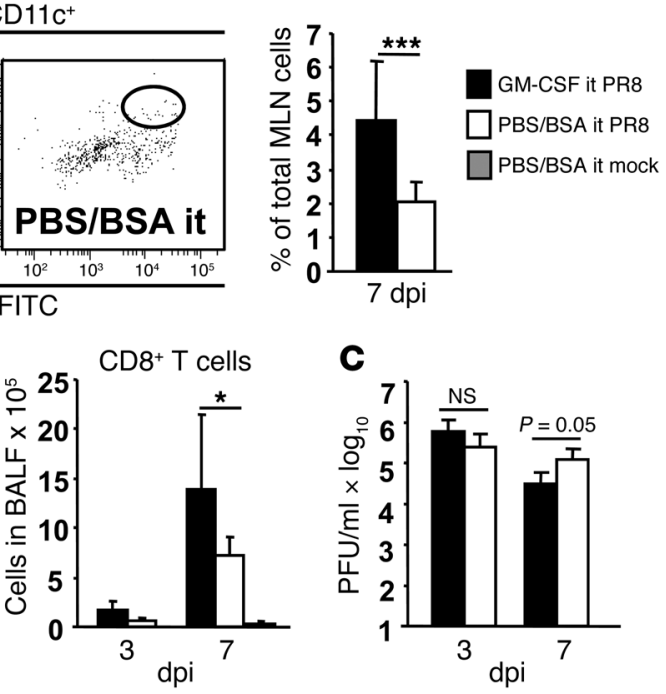

C

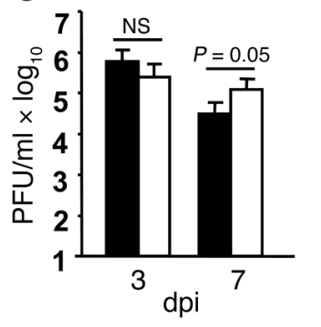

D

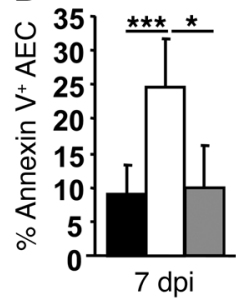

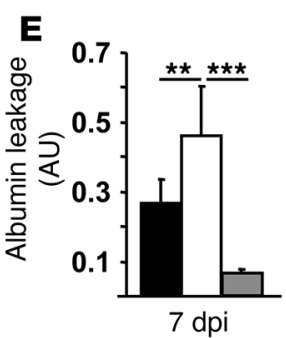

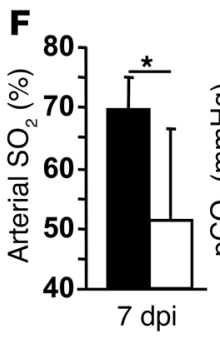

\section{Figure 7}

GM-CSF application i.t. increases CD103+ DC migration, alveolar T lymphocyte recruitment, and viral clearance, which is associated with attenuated lung injury after PR8 infection. WT mice were PR8 infected (or mock infected in selected experiments), followed by i.t. application of $5 \mu \mathrm{g}$ GM-CSF or PBS plus $0.1 \%$ BSA. (A) At 7 dpi, the fraction of $\mathrm{CD} 103^{+} \mathrm{DCs}$ in MLNs was quantified by flow cytometry. (B) Absolute numbers of $\mathrm{CD}^{+}$and $\mathrm{CD}^{+} \mathrm{T}$ lymphocytes in BALF were determined by counting BALF cells and flow cytometric quantification of the $\mathrm{CD} 45^{+} \mathrm{SSC}^{\circ} \mathrm{CD} 3^{+} \mathrm{CD} 4^{+}$ and $\mathrm{CD}_{4}{ }^{+} \mathrm{SSC}^{\mathrm{lo}} \mathrm{CD} 3^{+} \mathrm{CD} 8{ }^{+}$fractions, respectively, and (C) PR8 titers were determined from BALF by standard plaque assay. (D-F) At 7 dpi, AEC apoptosis (D), alveolar albumin leakage (given as ratio of BALF and serum FITC fluorescence in arbitrary units; $\mathrm{E}$ ), and arterial oxygen saturation and partial $\mathrm{CO}_{2}$ pressure $\left(\mathrm{pCO}_{2} ; \mathbf{F}\right)$ were determined. Data are mean \pm SD. ${ }^{\star} P<0.05,{ }^{\star \star} P<0.01,{ }^{* \star \star} P<0.005$. compared with WT and SPC-GM mice (Figure 5D). Of note, AEC GM-CSF, but not leukocyte-expressed GM-CSF, was required for efficient PR8 clearance at $7 \mathrm{dpi}$, as shown in $\mathrm{WT} \rightarrow G m-c s f^{-1}$ and $G m-c s f^{\prime-} \rightarrow$ WT chimeric mice, and AEC GM-CSF overexpression in SPC-GM mice even resulted in accelerated clearance compared with WT mice (Figure 5D). We concluded that AEC GM-CSF mediates recruitment of IFN- $\gamma^{+} \mathrm{T}$ cells to the lung, which is associated with enhanced clearance of infection.

AEC GM-CSF is required for effective host defense functions of CD $103^{+}$ $D C$ and for recovery from IV-induced lung injury. To definitely demonstrate the role of $\mathrm{CD} 103^{+} \mathrm{DC}$ activation in response to AEC GM-CSF for effective antiviral host defense and recovery from lung damage, we generated BM chimeras using WT or SPC-GM mice that were irradiated and reconstituted with Langerin ${ }^{+/ D T R}$ BM for 28 days. In this model, all pulmonary CD $103^{+}$DCs were of Langerin ${ }^{+}$DTR (donor) phenotype (data not shown) and selectively depleted by DTX application 48 hours prior to PR8 infection (Figure 6A). The representative FACS plots in Figure $6 \mathrm{~B}$ demonstrate high depletion efficiency in lungs of Langerin ${ }^{+/ D T R}$ chimeric mice treated with DTX compared with PBS-treated controls. Flow cytometric quantification of DCs in draining MLNs at 7 dpi with PR8 revealed that the $\mathrm{CD} 103^{+}$, but not the CD $11 \mathrm{~b}^{+}$, DC subset was significantly reduced in DTX- versus PBS-treated chimeras of both WT and SPC-GM recipient phenotypes (Figure 6C). CD $103^{+}$DC depletion resulted in reduced numbers of IFN $-\gamma^{+} \mathrm{CD} 4^{+}$and IFN $-\gamma^{+} \mathrm{CD} 8^{+}$ $\mathrm{T}$ cells in BALF at $7 \mathrm{dpi}$. Of note, $\mathrm{CD}^{+}$cytotoxic $\mathrm{T}$ cells in particular were reduced to equally low numbers in BALF of both WT and SPC-GM chimeric mice (Figure 6D). Accordingly, IV clearance decreased in WT and SPC-GM chimeric mice after DTX treatment to comparable levels at $7 \mathrm{dpi}$ (Figure 6E), which indicates that the beneficial effect of AEC SPC-GM overexpression on antiviral host defense was completely abrogated upon CD103+ DC depletion. Analyses of lung injury parameters revealed similarly increased AEC apoptosis and alveolar protein leakage in DTX-treated WT and SPC-GM chimeric mice compared with PBS-treated controls at $7 \mathrm{dpi}$ (Figure 6, F and G). Finally, whereas all PBS-treated SPC-GM chimeras survived infection until $21 \mathrm{dpi}$, survival of DTX-treated SPC-GM and WT chimeric mice was substantially decreased (Figure $6 \mathrm{H}$ ). Together, these data demonstrated that pulmonary $\mathrm{CD}_{103^{+}}$DCs are essential for AEC GM-CSFmediated host defense functions, which lead to recovery from lung injury in PR8 pneumonia.

Intratracheal deposition of recombinant $G M$-CSF increases $\mathrm{CD}_{103^{+}} \mathrm{DC}$ migration and host defense and attenuates IV-induced lung injury. The beneficial effects of high AEC GM-CSF levels in IV pneumonia in SPC-GM mice prompted us to evaluate whether exogenously applied GM-CSF would be similarly protective in our model. We therefore infected WT mice with PR8 and on the same day applied a single dose of recombinant GM-CSF intratracheally (i.t.). CD $103^{+} \mathrm{DC}$ numbers were significantly increased at $7 \mathrm{dpi}$ in MLNs of GM-CSF- versus control-treated mice (Figure 7A). Concomitantly, we found significantly increased numbers of $\mathrm{CD}^{+}$ and $\mathrm{CD}^{+} \mathrm{T}$ cells in BALF (Figure $7 \mathrm{~B}$ ) and reduced viral titers at $7 \mathrm{dpi}(P=0.05$; Figure $7 \mathrm{C})$ after GM-CSF treatment. In addition, PR8-induced lung injury at $7 \mathrm{dpi}$ was strikingly attenuated in GM-CSF-treated mice, as demonstrated by analyses of AEC apoptosis, alveolar albumin leakage, and arterial oxygen saturation partial $\mathrm{CO}_{2}$ pressure (Figure $7, \mathrm{D}-\mathrm{F}$ ). Together, these findings highlighted the role of GM-CSF, naturally released from lung epithelium upon IV infection, in antiviral DC host defense and suggest local GM-CSF delivery for further evaluation as a potential treatment strategy in severe IV pneumonia. 


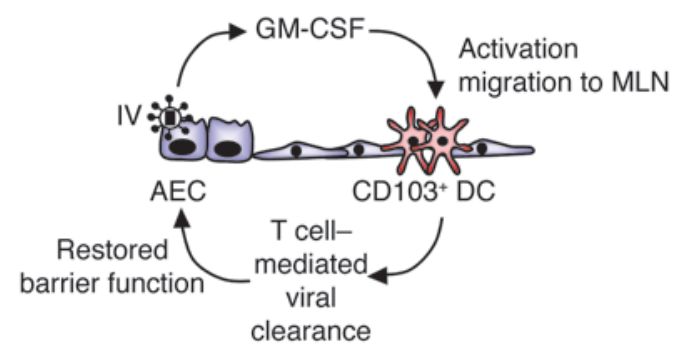

Figure 8

AEC GM-CSF mediates recovery from IV-induced lung injury by improving antiviral host defense functions of pulmonary CD103+ DCs. IV infection induces GM-CSF in AECs, which is particularly required for activation and migration of $\mathrm{CD}_{103}{ }^{+} \mathrm{DCs}$ to the draining MLNs. By its effects on $\mathrm{CD}_{103^{+}} \mathrm{DCs}$, epithelial GM-CSF increases the recruitment of IFN- $\gamma^{+} \mathrm{CD} 4^{+}$and IFN- $\gamma^{+} \mathrm{CD} 8^{+} \mathrm{T}$ cells to the air spaces, accelerates IV clearance, and mediates recovery from epithelial injury.

\section{Discussion}

IV pneumonia is characterized by infection of distal bronchiolar and, importantly, AECs and frequently progresses to acute lung injury/ARDS with poor outcome. Rapid onset of effective host defense strategies is therefore crucial for attenuation of or recovery from IV-induced lung injury. Pulmonary DC subsets are key regulators of antiviral innate and adaptive immune responses (13, 28-30). It is widely recognized that conventional DCs or their precursors are expanded at sites of inflammation or infection by defined chemokine-receptor interactions $(16,31,32)$, and that they are armed with a variety of pattern recognition receptors enabling them to sense foreign antigen, including viruses, and inducing their further activation (33). Yet, the mechanisms of communication between primary viral target cells in the distal lung and juxtaposed parenchymal DCs, which might be a critical link for infection-driven DC expansion or full activation, are poorly defined. We therefore tested the hypothesis that AEC-derived signals mediate expansion and host defense functions of pulmonary DC subsets in a mouse model of severe IV pneumonia. In fact, our data demonstrated that IVs induce the growth factor GM-CSF in AECs in vitro and in vivo, which was required not only for expansion of mo-DCs and CD $11 b^{+}$DCs in the lung, but particularly for activation and migration of $\mathrm{CD} 103^{+}$DCs to the draining MLNs. By its effects on $\mathrm{CD} 103^{+}$DCs, epithelial GM-CSF increases recruitment of IFN- $\gamma^{+} \mathrm{CD} 4^{+}$and IFN $-\gamma^{+} \mathrm{CD}^{+} \mathrm{T}$ cells to the air spaces, accelerates IV clearance, and mediates recovery from epithelial injury in terms of improved barrier function and gas exchange (Figure 8).

Initially considered to function solely as a physical barrier providing gas exchange, the alveolar epithelium is now increasingly recognized as an important effector in fine-tuning antiviral immune responses at both onset and resolution of inflammation $(4,5,34)$. Mononuclear phagocyte homeostasis, in particular, is controlled by such tissue-specific microenvironmental factors that either maintain a threshold for responsiveness to avoid continuous or excess inflammation (35) or establish immune competence before activation or after contact with antigen (36). Notably, the intimate spatial proximity of the resident DC network with the distal lung epithelium provides an ideal basis for direct cell-cell communication to maintain DC homeostasis in steady state or shape an effective immune response toward invading pathogens. Hammad et al. recently demonstrated that the initial scanning behavior of lung
DCs as well as their directed migration to the MLNs in response to LPS inhalation was largely dependent on TLR4 signaling by epithelial cells (37), supporting the concept that epithelial cell-DC crosstalk is required as a first step to initiate DC responses at the outer surface of the lung. The finding that parenchymal cells instruct the functional behavior of DCs, however, seems to be rather specific to mucosal surfaces, as Nolte et al. found no evidence for stromal instruction of splenic DCs to systemically administered antigens using a chimeric mouse model (38).

We and others have previously demonstrated that AECs are a substantial source of GM-CSF in the inflamed distal lung $(39,40)$, and GM-CSF was shown to be induced in a TLR-dependent way in alveolar epithelium following bacterial challenge in vitro (41). Nonetheless, leukocytes of lymphoid and myeloid lineages, especially resident macrophages, were also found to be sources of GM-CSF in inflamed tissues (42). Of note, our data from BM chimeric mice deficient in either leukocyte or parenchymal cell GM-CSF clearly indicated that lung parenchymal, but not leukocyte-derived, GM-CSF induced the observed effects on DCs in IV infection. These findings are reinforced by the fact that first, Gm-csf gene expression was highly expressed in ex vivo IV-infected primary murine or human AECs, and second, type II AECs were the only CD45- cell population in the distal lung parenchyma that upregulated GM-CSF upon infection (Figure 1 and Supplemental Figure 1). Given that parenchymal DCs and AECs reside in direct cell-to-cell contact within the lung parenchyma, epithelial GM-CSF can be expected to preferentially reach intra- or subepithelial DC populations. In this regard, previous findings on human lung sections demonstrated a role of GM-CSF expressed by hyperplastic type II AECs in mediating accumulation of CD1 $\mathrm{a}^{+}$DCs adjacent to these cells in inflamed lungs and in regions of lung tumors (43), which suggests that GM-CSFdependent AEC-DC cross-talk is similarly operative in human lung disease. Whether a similar mechanism of epithelial cell-DC interaction exists in the larger conducting airways or trachea will need to be defined in future studies.

We demonstrated that epithelial GM-CSF, at least in part, contributed to the expansion of mo-DCs and of CD $11 b^{+}$DCs in IVinfected lungs, but was not required for the presence of these DC subsets in the lung under noninfectious conditions (Figure 3, B and C) or for CD11 b ${ }^{+}$DC homeostasis in draining MLNs (Figure 4A). Based on previous studies by us and others $(44,45)$, we assume that the inflammation-triggered expansion of CD $11 b^{+}$DCs results primarily from increased recruitment of inflammatory precursors, rather than from local expansion of the tissue-resident subepithelial CD $11 b^{+}$DC pool. It is likely that pulmonary GM-CSF directly or indirectly mediates extravasation of mo-DC precursors that further differentiate toward a CD11 $b^{+}$DC phenotype within the inflammatory alveolar microenvironment.

In contrast to our findings on $\mathrm{CD} 11 \mathrm{~b}^{+} \mathrm{DCs}, \mathrm{CD} 103^{+} \mathrm{DC}$ development in the lung parenchyma was strongly dependent on GM-CSF in noninflammatory conditions. Expression of AEC GM-CSF in SPC-GM mice was sufficient to revert the reduced CD $103^{+}$DC numbers observed in Gm-csf $f^{--}$animals (Figure 3D). Given that $\mathrm{CD}_{103}{ }^{+} \mathrm{DCs}$ are replenished from circulating pre-DC pools (15), we speculate that lung-expressed GM-CSF might provide either a direct or an indirect recruitment signal for blood-borne pre-DCs or induce local proliferation of differentiated $\mathrm{CD} 103^{+}$parenchymal DCs. Of note, we did not detect any leakage of epithelial GM-CSF into the circulation in WT or SPC-GM mice (data not shown). Interestingly, constitutive alveolar overexpression of GM-CSF 
did not further increase the numbers of steady-state lung CD103+ DCs in SPC-GM versus WT mice, with BALF GM-CSF levels of $595 \pm 75 \mathrm{pg} / \mathrm{ml}$ compared with $47 \pm 14 \mathrm{pg} / \mathrm{ml}$ in untreated mice (data not shown). This might be due to the requirement of a second signal, such as Flt $3 \mathrm{~L}$, that additionally determines the numbers of tissue $\mathrm{CD}_{103}{ }^{+} \mathrm{DCs}$ in steady state. Remarkably, baseline $\mathrm{CD} 103^{+} \mathrm{DC}$ numbers in draining MLNs were significantly increased upon conditional and exclusive GM-CSF overexpression in the lung. Although we lack direct evidence that CD103 ${ }^{+}$ DCs accumulating in MLNs are lung derived, these data suggest an enhanced migratory capacity of AEC GM-CSF-stimulated pulmonary $\mathrm{CD}_{103^{+}} \mathrm{DCs}$, which is likely due to increased baseline activation of $\mathrm{CD}_{103}{ }^{+} \mathrm{DCs}$ in terms of CD80 expression, as observed in SPC-GM mice (Figure 4, B and E).

GM-CSF was widely used in clinical studies to attract or generate DCs at sites of disease $(46,47)$. The question of whether and to what extent GM-CSF controls the homeostasis of resident organ DCs and their functional properties during inflammatory diseases, however, is still controversial. Whereas systemic GM-CSF is not involved in lymphoid organ DC development in the steady state (48), it was previously shown to play a role during inflammation (49), which suggests that GM-CSF might preferentially regulate the development of inflammatory DCs. Recently, however, several studies using GM-CSFR-deficient mice elucidated a role of the GM-CSF/GM-CSFR axis in the development of steady-state DCs in nonlymphoid tissues. Whereas Bogunovic et al. showed that GM-CSFR controls the development of CD $103^{+} \mathrm{CD} 11 \mathrm{~b}^{+} \mathrm{DCs}$, but not $\mathrm{CD} 103^{-} \mathrm{CD} 11 \mathrm{~b}^{+} \mathrm{DCs}$, in the gut lamina propria (24), another study revealed that lack of GM-CSFR compromises the development of lamina propria CD11b+ DCs, but not CD11b- DCs (25). In the skin, GM-CSF was directly required for the accumulation of langerin ${ }^{+} \mathrm{CD} 103^{+}$DCs in peripheral lymph nodes under both steady-state and inflammatory conditions (26). With respect to the lung, Ginhoux et al. revealed that under noninflammatory conditions, both $\mathrm{CD}_{103}{ }^{+}$and $\mathrm{CD} 11 \mathrm{~b}^{+}$DCs depended on the Flt3/Flt3L system, whereas $\mathrm{CD} 11 \mathrm{~b}^{+} \mathrm{DC}$ development additionally required M-CSFR signaling, but the role of the GM-CSF/GM-CSFR axis was not explored in this study (14). Our data added to the aforementioned reports and revealed what we believe to be a new role of tissue-expressed GM-CSF in steady-state turnover of lung and MLN CD $103^{+}$DCs. Importantly, we demonstrated a role of AEC GM-CSF in expanding inflammatory DC subsets and in improving resident lung DC host defense capacities during infection.

Upon IV infection and antigen sampling, CD $103^{+}$DCs left the lung parenchyma (Figure 3D) and accumulated in the draining MLNs until 7 dpi (Figure 4, B and E), which has been described previously for this DC subset (13). Although lung CD $103^{+}$DC numbers were already low in untreated $\mathrm{Gm}$-csf $f^{/-}$mice, we revealed that their capacity to migrate to MLNs in response to infection was additionally reduced compared with mice expressing epithelial GM-CSF (Figure 4D). This was associated with decreased expression of surface maturation markers on $\mathrm{CD} 103^{+} \mathrm{DCs}$ in the lung, most prominently found for CD80 at 7 dpi. Remarkably, in Gm-csf/- mice, the levels of costimulatory molecules on migratory $\mathrm{CD} 103^{+}$DCs were still decreased after reaching the MLNs, suggestive of reduced potential to cross-present antigen to naive $\mathrm{T}$ cells and to create specific effectors, a primary task of this DC subset (12). Our findings on GM-CSF-dependent DC activation were in line with recent data identifying GM-CSF as a major licensing factor of $\mathrm{CD}^{+} \mathrm{T}$ lymphocytes to activate DCs during priming in lymphoid tissue. Signaling through the GM-CSFR in ex vivo-purified DCs was found to upregulate the expression of costimulatory molecules more efficiently than did any other inflammatory stimulus and provided a positive feedback loop in the stimulation of $\mathrm{CD}^{+} \mathrm{T}$ cell proliferation (50).

Indeed, we found reduced accumulation of antigen-specific $\mathrm{CD}^{+}$and $\mathrm{CD}^{+} \mathrm{T}$ cells in the spleen and airspaces in $\mathrm{Gm}$-csf $\mathrm{f}^{--}$ mice compared with mice expressing lung epithelial GM-CSF, an effect associated with increased viral titers (Figure 5). Depletion of langerin ${ }^{+} \mathrm{CD} 103^{+}$DCs nearly completely abrogated the generation and alveolar recruitment of IFN- $\gamma^{+} \mathrm{CD}^{+} \mathrm{T}$ cells in both WT and SPC-GM chimeric mice and significantly reduced $\mathrm{CD}^{+} \mathrm{T}$ cell responses, confirming previous data on the role of $\mathrm{CD}_{103}{ }^{+} \mathrm{DCs}$ in IV clearance (13) and indicating that the beneficial effects of AEC GM-CSF on the immune response toward IVs were mediated by the $\mathrm{CD} 103^{+} \mathrm{DC}$ subset. Of note, recovery from IV-induced lung injury in terms of epithelial cell apoptosis, protein leakage, and, finally, survival largely depended on the presence of CD $103^{+}$DCs (Figure 6).

Lack of strategies to specifically target resident or inflammatory recruited lung $\mathrm{CD} 11 \mathrm{~b}^{+} \mathrm{DCs}$ has retarded similar approaches for this cell type. Although we did not detect substantial accumulation of CD $11 b^{+}$DCs in the draining MLNs in response to IV infection, we cannot exclude a contribution of GM-CSF-dependent expansion or activation of this DC subset to adaptive anti-influenza host defense. Recent data demonstrated that protective IVspecific $\mathrm{CD}^{+} \mathrm{T}$ cell responses required interactions with DC subsets directly within the lung tissue. Apart from other DC subsets, lung tissue-recruited, nonmigrating CD $11 b^{+}$DCs significantly contributed to mounting effective local cytotoxic $\mathrm{T}$ cell responses and IV clearance (51), which is likely to occur to an undefined extent in our model. In addition, we previously demonstrated that lung-recruited inflammatory $\mathrm{CD} 11 \mathrm{~b}^{+} \mathrm{DCs}$ are a primary source of innate immune mediators like TNF- $\alpha$ or IL-12p40 (45).

It is well established that AEC GM-CSF improves innate immune responses of myeloid cells, in particular alveolar macrophages, and increases their survival, which was recently shown to be protective during IV infection in vivo $(22,23,52)$. Our present data suggest that GM-CSF overexpression accelerates viral clearance by 3 dpi, when innate immunity responses are prominent. Using WT and SPC-GM chimeric mice transplanted with CD11c ${ }^{+/ D T R}$ BM to deplete DCs, combined with clodronate-induced depletion of alveolar macrophages, we differentially addressed their respective contributions in the context of high-level AEC GM-CSF. Indeed, depletion of macrophages alone reduced survival by $25 \%$ compared with nondepleted mice after IV challenge. However, additional depletion of lung DCs before infection was $100 \%$ lethal, regardless of whether these mice displayed normal or increased GM-CSF levels in their lungs (Figure 2). We therefore conclude that the lung-protective effects of GM-CSF in our model are largely mediated through its actions on DCs, although improved macrophage (or neutrophil) activity in SPC-GM mice likely contributes to early antiviral host defense and prevention of lung injury. In this respect, we and others have shown that AEC GM-CSF critically mediates epithelial proliferation in inflammatory or hyperoxic lung injury, thereby actively supporting repair and restoration of barrier function and return to tissue homeostasis (39, 53). Therefore, based on the beneficial effects observed for i.t. GMCSF treatment regarding $\mathrm{CD} 103^{+} \mathrm{DC}$ antiviral functions in our model (Figure 7) and its beneficial effects described in others (21), 
local therapeutic application of GM-CSF might be considered to increase mononuclear phagocyte-mediated innate and adaptive host defense and to accelerate epithelial repair processes during severe IV pneumonia.

\section{Methods}

Reagents. The following anti-mouse mAbs/secondary reagents were used for flow cytometry: CD45.1-PE and -FITC (clone A20), CD45-FITC, -PE, and -APC (clone 30F-11), CD45.2-PerCp-Cy5.5 (clone 104), I-A/I-E-FITC (clone 2G9), SiglecF-PE (clone E502440), CD31-PE (clone MEK13.3), CD4-FITC (clone RM4-4), CD8-PE-Cy7 (clone 53-6.7), CD11c-APC (clone HL3), CD11b-PE (clone M1/70), B220-PE-Cy7 (clone RA3-6B2), CD80-PE (clone 16-10A1), CD86-PE-Cy7 (clone GL1), and isotype-matched control IgG Abs (all BD Biosciences - Pharmingen); CD45.2-APC-Cy7 (clone 104), CD3-PerCP (clone 145-2C11), CD103-PerCP (clone 2E7), EpCam-APCCy7 and -eFluor450 (clone g8.8), CD31-Alexa Fluor 488 (clone MEK13.3), $\mathrm{T} 1 \alpha /$ podoplanin-PE-Cy7 (clone 8.1.1), CD49f-PE (clone GoH3), IFN- $\gamma$-APC (clone XMG1.2), and isotype-matched control IgG-APC (all Biolegend); F4/80-Alexa Fluor 647 (clone CI:A3-1; Caltag); anti-influenza NP (Biodesign); NP-FITC (clone 431; Abcam), pro-surfactant protein C (pro-SPC; Millipore), annexin V-Alexa Fluor 647 (Molecular Probes); antimouse Ig-Alexa Fluor 488 (Molecular Probes). Propidium iodide for dead cell exclusion was purchased from Sigma-Aldrich. Influenza antigen-specific $\mathrm{T}$ cells were detected by FACS using PE-labeled H-2 $\mathrm{D}^{\mathrm{b}}$ dextramer with the NP 366-374 epitope ASNENMETM or PE-labeled nonspecific control dextramer (Immudex).

Mice. C57BL/6 WT mice were purchased from Charles River Laboratories. Gm-csf ${ }^{/-}$mice were produced on a C57BL/6 background (54). Transgenic SPC-GM mice, which overexpress GM-CSF in AECs, were generated in $G m-c s f /$ mice by expression of a chimeric gene containing GM-CSF under control of the human SP-C promoter (55). Gm-csf $f^{\prime-}$ and SPC-GM mice were a gift from J. Whitsett (University of Cincinnati, Cincinnati, Ohio, USA). B6.SJL-Ptprc ${ }^{d}$ mice, expressing the CD45.1 alloantigen (Ly5.1 PTP) on circulating leukocytes, and CD11 $\mathrm{c}^{+/ \mathrm{DTR}}$ mice (both C57BL/ 6 genetic background) were obtained from The Jackson Laboratory. CD $11 \mathrm{c}^{+/ \mathrm{DTR}}$ mice (56) were mated with C57BL/6 WT mice, and the heterozygous offspring were used for experiments. Langerin ${ }^{\mathrm{DTR} / \mathrm{DTR}}$ mice were generated as previously described (57) and mated with C57BL/6 WT mice to obtain Langerin ${ }^{+/ D T R}$ mice. Animals were kept under specific pathogen-free (SPF) conditions and used at 8-11 weeks of age.

Treatment protocols. Mice were inoculated i.t. with $500 \mathrm{PFU}$ (except where otherwise indicated) IV A/PR/8/34 (PR8; H1N1; gift from S. Pleschka, Institute of Medical Virology, University of Giessen, Giessen, Germany). PR8 was grown and quantified in madin darby canine kidney (MDCK) cells and diluted in a total volume of $70 \mu \mathrm{l}$ sterile $\mathrm{PBS}^{-/}$. BALF and venous blood were obtained and processed as described elsewhere (58). BALF cells were counted with a hemocytometer and processed for flow cytometric analyses, or differential cell counts of Pappenheim-stained cytocentrifuge preparations were performed. Alveolar albumin leakage was analyzed by i.v. injection of FITC-labeled albumin (Sigma-Aldrich) and quantification of FITC fluorescence in BALF and serum, as previously described (58). Total BALF protein was quantified using the Dc Protein Assay Kit (Biorad) and calculated with SoftMaxPro Software (Molecular Devices). Arterial blood was obtained by left ventricular puncture, and blood gases were determined in an ABL5 blood gas analyzer (Radiometer). Spleens were minced and digested in RPMI 1640 supplemented with $1 \mathrm{mg} / \mathrm{ml}$ collagenase A (Sigma-Aldrich) and $0.05 \mathrm{mg} / \mathrm{ml}$ DNAse (Serva) for quantification of antigen-specific lymphocytes. For preparation of LHs, perfused lungs were filled with sterile Dispase (BD Biosciences) and $0.5 \mathrm{ml}$ low-melting agarose (Sigma-Aldrich) via the trachea, removed after gelling, and placed in Dispase for 40 minutes at room temperature. The distal lung parenchyma was subsequently separated from the bronchial tree, minced in DMEM/2.5\% HEPES with $0.01 \%$ DNase (Serva), and successively passed through 100- and 40- $\mu \mathrm{m}$ nylon filters. Obtained distal LH cells were counted and subjected to flow cytometric analysis as described above. Lung digests were composed of $\mathrm{CD} 45^{+}$leukocytes, CD31+ endothelial cells, and EpCam ${ }^{+}$cells, which were mainly type II ( 93\%) and type I ( 4\%) AECs. In selected experiments, LH cells were subjected to CD $45^{+}$selection by magnetic separation using a MACS separation kit according o the manufacturer's instructions (Miltenyi Biotech) prior to further analyses. For RNA isolation and cytokine quantification, perfused lungs were removed, homogenized with a Tissue Homogenizer (Qiagen), and centrifuged. Supernatants and remaining tissue pellets were stored for further processing. 2-3 mediastinal lymph nodes per animal were digested in Dispase for 40 minutes at room temperature and subsequently processed for flow cytometric analyses. In selected experiments, $5 \mu \mathrm{g}$ recombinant murine GM-CSF (R\&D Systems) in $50 \mu$ l endotoxin-free PBS/0.1\% BSA or $\mathrm{PBS} / 0.1 \%$ BSA alone were i.t. applied directly after PR8 or mock infection. Lung macrophages were depleted by i.t. instillation of $50 \mu \mathrm{l}$ clodronateloaded liposomes 48 hours prior to infection (Sigma-Aldrich). Empty liposome instillation served as control (Coatsome EL; NOF Corp.). DTX (Sigma-Aldrich) was either applied i.p. to deplete CD11 $\mathrm{c}^{+/ \mathrm{DTR}}$ cells $(600 \mathrm{ng})$ or i.t. (50 ng) plus i.p. (400 ng) to deplete Langerin $/$ DTR cells.

Lung virus titers. Virus titers were determined by immunohistochemistrybased plaque assay on confluent MDCK cells in 6-well plates in duplicates. Briefly, cells were incubated with $1 \mathrm{ml}$ serial BALF dilutions for 1 hour and covered for 48 hours with Avicel (FMC Biopolymer) medium (50\% v/v $2 \times \mathrm{MEM}, 50 \% \mathrm{v} / \mathrm{v}$ of $2.5 \%$ Avicel in $\mathrm{H}_{2} \mathrm{O}$ solution, $1 \% \mathrm{v} / \mathrm{v}$ penicillin-streptomycin, $1.5 \% \mathrm{v} / \mathrm{v}$ of $7.5 \% \mathrm{NaHCO}_{3}, 0.1 \% \mathrm{v} / \mathrm{v}$ Trypsin, $\left.0.3 \% \mathrm{v} / \mathrm{v} \mathrm{BSA}\right)$. After overlay removal, cells were fixed, permeabilized, and stained with anti-NP $\mathrm{mAb}$ for 1 hour, followed by 1 hour staining with peroxidase-labeled antimouse $\mathrm{Ab}$ (Dako) and 10 minutes incubation with TrueBlue peroxidase substrate (KPL) before quantification of stained plaques (detection limit, $10 \mathrm{PFU} / \mathrm{ml}$ BALF).

Flow cytometry and cell sorting. Multiparameter flow cytometry was performed using FACSCanto and LSR Fortessa flow cytometers equipped with DIVA software (BD Biosciences). $1-5 \times 10^{5}$ cells per sample of BALF, LH, or MLNs were fixed for 15 minutes in cold $1 \%$ paraformaldehyde and incubated with fluorochrome-labeled antibodies for 20 minutes at $4{ }^{\circ} \mathrm{C}$. For intracellular stainings (NP, IFN- $\gamma$, pro-SPC), cells were subsequently incubated for 15 minutes in $0.2 \%$ saponin in PBS and incubated with anti-NP $\mathrm{mAb}$, IFN- $\gamma$-APC, or anti-pro-SPC or respective isotype control mAbs for 30 minutes at $4{ }^{\circ} \mathrm{C}$, followed by 30 minutes incubation with secondary antimouse-Alexa Fluor $488 \mathrm{Ab}$ in case of NP staining. Apoptosis analysis was performed on freshly prepared, nonfixed, nonpermeabilized LHs. Prior to antibody incubation, the samples were washed and resuspended in annexin V buffer (10 mM HEPES, $140 \mathrm{mM} \mathrm{NaCl}, 2.5 \mathrm{mM} \mathrm{CaCl}_{2}$ ). Immediately thereafter, cells were costained with respective mAbs and annexin V-647 in annexin $\mathrm{V}$ buffer for 20 minutes at $4^{\circ} \mathrm{C}$. Cell sorting was performed using a FACSAriaIII equipped with 4 lasers and DIVA Software (BD Biosciences). The purities of sorted lung cell populations were always $>93 \%$.

ELISA. GM-CSF levels in LHs and serum were analyzed using a commercially available ELISA kit (R\&D Systems) according to the manufacturer's instructions (detection limit, $1.8 \mathrm{pg} / \mathrm{ml}$ ).

Isolation, culture, and infection of murine and human AECs. Murine AECs were isolated as described previously $(39,59)$. LHs were prepared as described above; the single-cell suspension was centrifuged, resuspended, and incubated with biotinylated rat anti-mouse CD45, CD16/32, and CD31 mAbs (all BD Biosciences - Pharmingen) to deplete leukocytes and endothelial cells for 30 minutes. The contaminating cell types were removed by incuba- 
tion with streptavidin-linked magnetic particles and subsequent magnetic separation. The supernatant was recovered, and cells were kept in DMEM supplemented with FCS, HEPES, L-glutamine, and penicillin-streptomycin. AECs from human lung tissue were isolated as described previously (58). The lung tissue was minced and washed extensively in HAM F12 medium containing $10 \%$ FCS and antibiotics, filtered through $100-\mu \mathrm{m}$ pore size filters (BD Biosciences), and subsequently digested with Dispase II $(2.5 \mathrm{mg} / \mathrm{ml}$; Boehringer $)$ in the presence of $2 \mathrm{mM}$ calcium and $1.3 \mathrm{mM}$ magnesium for 180 minutes at $37^{\circ} \mathrm{C}$ under continuous rotation. A cellrich suspension was obtained by sequential filtration through sterilized 100 - and $40-\mu \mathrm{m}$ filters (BD Biosciences) and $20-\mu \mathrm{m}$ pore size meshes (Millipore). AECs were separated by ficoll (Ficoll Paque; Amersham Pharmacia Biotech) density centrifugation $\left(1,300 \mathrm{~g}\right.$ for 15 minutes at $\left.21^{\circ} \mathrm{C}\right)$, followed by depleting the interfacial cells of contaminating leukocytes by anti-CD 45 magnetic beads (Miltenyi Biotech). Final cell suspensions consisted of $>95 \%$ AECs, as assessed by FACS. Viability was always > $95 \%$, as analyzed by trypan blue dye exclusion. AECs were cultured for 5 (murine) or 7 (human) days in FCS- and antibiotics-supplemented DMEM and HAM F12 medium, respectively. Confluent AECs were infected or mock-infected with PR8 diluted in $\mathrm{PBS}^{-/-}$at the indicated MOI as previously reported (59).

Creation of BM chimeric mice. BM cells were isolated under sterile conditions from the tibias and femurs of WT, Gm-csf ${ }^{--}, \mathrm{CD} 11 \mathrm{c}^{+/ \mathrm{DTR}}$, or Langerin ${ }^{+/ \mathrm{DTR}}$ donor mice as described previously (4). $1 \times 10^{6} \mathrm{BM}$ cells were i.v. injected into lethally irradiated WT, Gm-csf/-, or SPC-GM recipient mice after total body irradiation (6 Gy). As engraftment controls, WT BM cells (expressing the CD45.2 alloantigen) were transplanted into CD45.1 alloantigen-expressing C57BL/ 6 mice $(n=4$ per transplantation experiment), and the proportion of CD $45.2^{+}$myeloid blood leukocytes was analyzed by flow cytometry. BM engraftment was $94.4 \% \pm 1.6 \%$ at 4 or 8 weeks post transplantation. Chimeric mice were housed under SPF conditions prior to PR8 infection.

RNA isolation and real-time RT-PCR. RNA from cultured AECs and from murine lungs was isolated by PeqGold Total RNA kit (Peqlab) and RNeasy Kit (Qiagen), respectively, following the manufacturer's protocol. cDNA synthesis, reagents, and incubation steps were as previously described (39). Relative mRNA quantification was done by real-time RT-PCR, using actin as a reference gene. Reactions were performed in an ABI 7900 Sequence Detection System (Applied Biosystems) using SYBR-Green I as fluorogenic probe in $25-\mu \mathrm{l}$ reactions containing $12.5 \mathrm{ng}$ converted cDNA sample, $1 \times$ qPCR Mastermix for SYBR Green I (Invitrogen), and 45 pmol forward and reverse primers. The following intron-spanning primers were used: murine actin forward, 5'-ACCCTAAGGCCAACCGTGA-3'; murine actin reverse, 5'-CAGAGGCATACAGGGACAGCA-3'; murine GM-CSF forward, 5'-GAAGCATGTAGAGGCCATCA-3'; murine GM-CSF reverse, 5'-GAATATCTTCAGGCGGGTCT-3'; murine SP-C forward, 5'-TCCTGATGGAGAGTCCACCG-3'; murine SP-C reverse, 5'-CAGAGCCCCTACAATCACCAC-3'; human actin forward, 5'-CTGGGAGTGGGTGGAGGC-3'; human actin reverse, 5'-TCAACTGGTCTCAAGTCAGTG-3'; human GM-CSF forward, 5'-GTCTCACTCCTGGACTGGCT-3'; human GM-CSF reverse, 5'-ACTACAAGCAGCACTGCCCT-3'. Relative gene abundance to housekeeping gene was calculated as a $\Delta \mathrm{Ct}$ value (namely, $\left.C \mathrm{t}_{\text {reference }}-\mathrm{Ct}_{\text {target }}\right)$, and data are presented as $\Delta \mathrm{CT}$ or fold expression $\left(2^{\Delta \Delta \mathrm{Ct}}\right)$ values between treatment groups.

Statistics. All data are given as mean \pm SD. Statistical significance between 2 groups was estimated using the unpaired Student's $t$ test or ANOVA and post-hoc Tukey HSD for comparison of 3 groups and calculated with SPSS for Windows. A $P$ value less than 0.05 was considered significant.

Study approval. All animal experiments were approved by the regional authorities of the State of Hesse (Regierungspräsidium Giessen). Human lung tissue was obtained from patients who underwent lobectomy after informed written consent (Departments of Pathology and Surgery, Justus-Liebig-University, Giessen). Use of human lung tissue samples was approved by the University of Giessen Ethics Committee.

\section{Acknowledgments}

This work was supported by the German Research Foundation (SFB/TR84 "Innate Immunity of the lung" grants B2/3, grant LO271/4-1, and Excellence Cluster Cardio-Pulmonary System [ECCPS]), by the German Federal Ministry of Research and Education ("FluResearchNet" grant $01 \mathrm{KI} 1006 \mathrm{M}$ and Clinical Research Group "Infectious Diseases" grant 01 KI 0770), and by the von Behring-Röntgen Foundation of the Universities of Giessen and Marburg. B.E. Clausen is a VIDI-fellow of the Netherlands Organization for Scientific Research (NWO). The authors thank R. Winkler, J. Bespalowa, and D. Hensel for excellent technical assistance and J. Whitsett for providing $G m-c s f^{/-}$and SPC-GM mice.

Received for publication November 25, 2011, and accepted in revised form July 19, 2012.

Address correspondence to: Susanne Herold, University of Giessen Lung Center, Department of Internal Medicine II, Klinikstr. 36, D-35392 Giessen, Germany. Phone: 49.641.985.42552; Fax: 49.641.985.42568; E-mail: Susanne.Herold@innere.med.unigiessen.de.
1. Jain S, et al. Hospitalized patients with $2009 \mathrm{H} 1 \mathrm{~N} 1$ influenza in the United States, April-June 2009 NEngl J Med. 2009;361(20):1935-1944.

2. Kuiken T, Taubenberger JK. Pathology of human influenza revisited. Vaccine. 2008; 26(suppl 4):D59-D66

3. Mauad T, et al. Lung pathology in fatal novel human influenza A (H1N1) infection. Am J Respir Crit Care Med. 2010;181(1):72-79.

4. Herold $S$, et al. Lung epithelial apoptosis in influenza virus pneumonia: the role of macrophageexpressed TNF-related apoptosis-inducing ligand. J Exp Med. 2008;205(13):3065-3077.

5. Hufford MM, Kim TS, Sun J, Braciale TJ. Antiviral $\mathrm{CD} 8+\mathrm{T}$ cell effector activities in situ are regulated by target cell type. J Exp Med. 2011;208(1):167-180.

6. La Gruta NL, Kedzierska K, Stambas J, Doherty PC. A question of self-preservation: immunopathology in influenza virus infection. Immunol Cell Biol. 2007;85(2):85-92.

7. Hussell T, Goulding J. Structured regulation of inflammation during respiratory viral infection.
Lancet Infect Dis. 2010;10(5):360-366.

8. Lambrecht BN, Prins JB, Hoogsteden HC. Lung dendritic cells and host immunity to infection. Eur Respir J. 2001;18(4):692-704.

9. Legge KL, Braciale TJ. Accelerated migration of respiratory dendritic cells to the regional lymph nodes is limited to the early phase of pulmonary infection. Immunity. 2003;18(2):265-277.

10. Helft J, Ginhoux F, Bogunovic M, Merad M. Origin and functional heterogeneity of non-lymphoid tissue dendritic cells in mice. Immunol Rev. 2010; 234(1):55-75

11. Hao X, Kim TS, Braciale TJ. Differential response of respiratory dendritic cell subsets to influenza virus infection. J Virol. 2008;82(10):4908-4919.

12. Kim TS, Braciale TJ. Respiratory dendritic cell subsets differ in their capacity to support the induction of virus-specific cytotoxic CD8+ T cell responses. PLoS One. 2009;4(1):e4204.

13. GeurtsvanKessel $\mathrm{CH}$, et al. Clearance of influenza virus from the lung depends on migratory langerin+CD11b- but not plasmacytoid dendritic cells. J Exp Med. 2008;205(7):1621-1634.

14. Ginhoux F, et al. The origin and development of nonlymphoid tissue CD103+ DCs. JExp Med. 2009; 206(13):3115-3130.

15. Geissmann F, Manz MG, Jung S, Sieweke MH, Merad M, Ley K. Development of monocytes, macrophages, and dendritic cells. Science. 2010; 327(5966):656-661.

16. Lin KL, Suzuki Y, Nakano H, Ramsburg E, Gunn MD. CCR2+ monocyte-derived dendritic cells and exudate macrophages produce influenza-induced pulmonary immune pathology and mortality. JImmunol. 2008;180(4):2562-2572.

17. Hamilton JA. Colony-stimulating factors in inflammation and autoimmunity. Nat Rev Immunol. 2008;8(7):533-544.

18. Inaba $\mathrm{K}$, et al. Generation of large numbers of dendritic cells from mouse bone marrow cultures supplemented with granulocyte/macrophage colony-stimulating factor. J Exp Med. 1992; 176(6):1693-1702.

19. Ballinger MN, Paine R. Role of granulocyte macro- 
phage colony-stimulating factor during gram-negative lung infection with Pseudomonas aeruginosa. Am J Respir Cell Mol Biol. 2006;34(6):766-774.

20. LeVine AM, Reed JA, Kurak KE, Cianciolo E, Whitsett JA. GM-CSF-deficient mice are susceptible to pulmonary group B streptococcal infection. J Clin Invest. 1999;103(4):563-569.

21. Huang H, Li H, Zhou P, Ju D. Protective effects of recombinant human granulocyte macrophage colony stimulating factor on $\mathrm{H} 1 \mathrm{~N} 1$ influenza virus-induced pneumonia in mice. Cytokine. 2010; 51(2):151-157.

22. Huang FF, et al. GM-CSF in the Lung Protects against Lethal Influenza Infection. Am J Respir Crit Care Med. 2011;184(2):259-268.

23. Sever-Chroneos Z, et al. GM-CSF modulates pulmonary resistance to influenza A infection. Antiviral Res. 2011;92(2):319-328.

24. Bogunovic $M$, et al. Origin of the lamina propria dendritic cell network. Immunity. 2009;31(3):513-525.

25. Varol C, et al. Intestinal lamina propria dendritic cell subsets have different origin and functions. Immunity. 2009;31(3):502-512.

26. King IL, Kroenke MA, Segal BM. GM-CSFdependent, CD103+ dermal dendritic cells play a critical role in Th effector cell differentiation after subcutaneous immunization. J Exp Med. 2010; 207(5):953-961.

27. McQualter JL, Yuen K, Williams B, Bertoncello I. Evidence of an epithelial stem/progenitor cell hierarchy in the adult mouse lung. Proc Natl Acad SciUS A. 2010;107(4):1414-1419.

28. Ballesteros-Tato A, Leon B, Lund FE, Randall TD Temporal changes in dendritic cell subsets, crosspriming and costimulation via CD70 control CD8(+) T cell responses to influenza. Nat Immunol. 2010;11(3):216-224.

29. Belz GT, et al. Distinct migrating and nonmigrating dendritic cell populations are involved in MHC class I-restricted antigen presentation after lung infection with virus. Proc Natl Acad Sci U S A. 2004; 101(23):8670-8675.

30. Kim TS, Hufford MM, Sun J, Fu YX, Braciale TJ. Antigen persistence and the control of local $\mathrm{T}$ cell memory by migrant respiratory dendritic cells after acute virus infection. J Exp Med. 2010;207(6):1161-1172.

31. Osterholzer JJ, et al. CCR2 and CCR6, but not endothelial selectins, mediate the accumulation of immature dendritic cells within the lungs of mice in response to particulate antigen. J Immunol. 2005; 175(2):874-883.

32. Thorley AJ, Goldstraw P, Young A, Tetley TD. Primary human alveolar type II epithelial cell CCL20 (macrophage inflammatory protein-3alpha)induced dendritic cell migration. Am J Respir Cell Mol Biol. 2005;32(4):262-267.
33. Soloff AC, Barratt-Boyes SM. Enemy at the gates: dendritic cells and immunity to mucosal pathogens. Cell Res. 2010;20(8):872-885.

34. Sanders CJ, Doherty PC, Thomas PG. Respiratory epithelial cells in innate immunity to influenza virus infection. Cell Tissue Res. 2010;343(1):13-21.

35. Snelgrove RJ, et al. A critical function for CD200 in lung immune homeostasis and the severity of influenza infection. Nat Immunol. 2008;9(9):1074-1083.

36. Matzinger P. Friendly and dangerous signals: is the tissue in control? Nat Immunol. 2007;8(1):11-13.

37. Hammad H, Chieppa M, Perros F, Willart MA Germain RN, Lambrecht BN. House dust mite allergen induces asthma via Toll-like receptor 4 triggering of airway structural cells. Nat Med. 2009; 15(4):410-416

38. Nolte MA, Leibundgut-Landmann S, Joffre O, Reis e Sousa C. Dendritic cell quiescence during systemic inflammation driven by LPS stimulation of radioresistant cells in vivo. J Exp Med. 2007; 204(6):1487-1501.

39. Cakarova L, et al. Macrophage tumor necrosis factor-alpha induces epithelial expression of granulocyte-macrophage colony-stimulating factor: impact on alveolar epithelial repair. Am J Respir Crit Care Med. 2009;180(6):521-532

40. Sturrock A, et al. Mechanisms of suppression of alveolar epithelial cell GM-CSF expression in the setting of hyperoxic stress. Am J Physiol Lung Cell Mol Physiol. 2010;298(3):L446-L453.

41. Vardarova K, et al. PKC(alpha) and PKC(epsilon) differentially regulate Legionella pneumophila-induced GM-CSF. Eur Respir J. 2009;34(5):1171-1179.

42. Martinez-Moczygemba M, Huston DP. Biology of common beta receptor-signaling cytokines: IL-3, IL-5, and GM-CSF. J Allergy Clin Immunol. 2003; 112(4):653-665.

43. Tazi A, Bouchonnet F, Grandsaigne M, Boumsell L, Hance AJ, Soler P. Evidence that granulocyte macrophage-colony-stimulating factor regulates the distribution and differentiated state of dendritic cells/Langerhans cells in human lung and lung cancers. J Clin Invest. 1993;91(2):566-576.

44. Osterholzer JJ, Chen GH, Olszewski MA, Curtis JL, Huffnagle GB, Toews GB. Accumulation of $\mathrm{CD} 11 \mathrm{~b}+$ lung dendritic cells in response to fungal infection results from the CCR2-mediated recruitment and differentiation of Ly-6Chigh monocytes. J Immunol. 2009;183(12):8044-8053.

45. von Wulffen W, et al. Lung dendritic cells elicited by Fms-like tyrosine 3-kinase ligand amplify the lung inflammatory response to lipopolysaccharide. Am J Respir Crit Care Med. 2007;176(9):892-901.

46. Dranoff G, et al. Vaccination with irradiated tumor cells engineered to secrete murine granulocyte-macrophage colony-stimulating factor stimulates potent, specific, and long-lasting antitumor immunity. Proc Natl Acad Sci U S A. 1993; 90(8):3539-3543.

47. Simons JW, et al. Induction of immunity to prostate cancer antigens: results of a clinical trial of vaccination with irradiated autologous prostate tumor cells engineered to secrete granulocyte-macrophage colony-stimulating factor using ex vivo gene transfer. Cancer Res. 1999;59(20):5160-5168.

48. Vremec D, Lieschke GJ, Dunn AR, Robb L, Metcalf $\mathrm{D}$, Shortman K. The influence of granulocyte/macrophage colony-stimulating factor on dendritic cell levels in mouse lymphoid organs. Eur J Immunol. 1997;27(1):40-44.

49. Naik SH, et al. Intrasplenic steady-state dendritic cell precursors that are distinct from monocytes. Nat Immunol. 2006;7(6):663-671.

50. Min L, et al. Cutting edge: granulocyte-macrophage colony-stimulating factor is the major CD8+ T cellderived licensing factor for dendritic cell activation. J Immunol. 2011;184(9):4625-4629.

51. McGill J, Van Rooijen N, Legge KL. Protective influenza-specific CD8 $\mathrm{T}$ cell responses require interactions with dendritic cells in the lungs. J Exp Med. 2008;205(7):1635-1646.

52. Willinger T, et al. Human IL-3/GM-CSF knock-in mice support human alveolar macrophage development and human immune responses in the lung. Proc Natl Acad Sci U S A. 2010;108(6):2390-2395.

53. Paine R. Transgenic overexpression of granulocyte macrophage-colony stimulating factor in the lung prevents hyperoxic lung injury. Am J Pathol. 2003; 163(6):2397-2406.

54. Dranoff G, et al. Involvement of granulocyte-macrophage colony-stimulating factor in pulmonary homeostasis. Science. 1994;264(5159):713-716.

55. Huffman JA, Hull WM, Dranoff G, Mulligan RC, Whitsett JA. Pulmonary epithelial cell expression of GM-CSF corrects the alveolar proteinosis in GMCSF-deficient mice. J Clin Invest. 1996;97(3):649-655.

56. Jung $S$, et al. In vivo depletion of CD $11 \mathrm{c}+$ dendritic cells abrogates priming of CD8+ T cells by exogenous cell-associated antigens. Immunity. 2002; $17(2): 211-220$

57. Bennett CL, et al. Inducible ablation of mouse Langerhans cells diminishes but fails to abrogate contact hypersensitivity. J Cell Biol. 2005; 169(4):569-576

58. Herold S, et al. Exudate macrophages attenuate lung injury by the release of IL-1 receptor antagonist in gram-negative pneumonia. Am J Respir Crit Care Med. 2011;183(10):1380-1390.

59. Herold S, et al. Alveolar epithelial cells direct monocyte transepithelial migration upon influenza virus infection: impact of chemokines and adhesion molecules. J Immunol. 2006;177(3):1817-1824. 